Patil Prasad Vinayak

Chelladurai Sree Krishna Prabu

Nagarajan Vishwanath

Sha Om Prakash

http://dx.doi.org/10.21278/brod72102

ISSN 0007-215X

eISSN 1845-5859

\title{
NUMERICAL SIMULATION OF SHIP NAVIGATION IN ROUGH SEAS BASED ON ECMWF DATA
}

UDC 629.5.017:629.5.017.2

Original scientific paper

\begin{abstract}
Summary
Recently, several changes have been observed in the Earth's environment. This is also applicable to the ocean environment. The concept of weather routing has been applied for ship navigation for a long time. Many service providers offer weather routing service with the availability of high-quality satellite data. Unfortunately, not much information is available in the public domain as to how much the recent change in the weather pattern has affected ship navigation. The purpose of this paper is to fill this information gap. We investigate the influence of recent changes in the ocean environment on ship navigation. Weather data from ECMWF, namely ERA-Interim, is used for this purpose. The ECMWF data for the last 27 years is analysed. We compute the statistical characteristics of this data for the first 10 years, last 10 years, and 27 years. The statistical characteristics of the data are determined based on "summer" and "winter" zones as defined by international maritime regulations. Six different worldwide commercial ship routes are selected covering all the ocean regions. Navigation on great ellipse with waypoint is considered. MMG type ship manoeuvring model for 3 different ship types (DTMB 5415, PCC, VLCC) is used. The added resistance due to wave, wind and the effort of keeping the ship on the desired course using autopilot in the rough ocean environment is included in the MMG model. The fuel consumption and the duration of each one of the voyage are computed. Based on the analysis and simulation results it is shown that:

(i) The mean wave height, wave period, and wind speed has increased in some ocean zones and decreased in other ocean zones. If any change has occurred, it is uniform for both seasons (summer and winter).

(ii) In which ocean regions there is a perceptible change in fuel consumption, average ship speed and voyage time due to the changes in the weather pattern.

(iii) The changing weather pattern in different ocean zones affects each ship type differently.
\end{abstract}

Key words: $\quad$ Added resistance; ECMWF; ERA-interim; fuel consumption; great ellipse sailing; ship navigation; weather effects 
Patil Prasad Vinayak,

Chelladurai Sree Krishna Prabu,

Nagarajan Vishwanath, Sha Om Prakash
Numerical simulation of ship navigation in rough seas based on ECMWF data

\section{Introduction}

Nearly $90 \%$ of the world's trade is carried onboard ships. For some of these trades, there is no alternative to transporting cargo by ships. In recent years, the incidence of loss of ships (mostly bulk carriers) is increasing due to change in the wave pattern [1]. Effects of rough weather are loss of ship, damage to the ship, increased deck wetness, propeller emergence, slamming, vertical/ horizontal bending and torsion, worsened stability and manoeuvrability, and/or additional dynamic loads of the hull. It is risky to sail in a rough sea and strong wind. Hence, prior knowledge of weather conditions is important in the study of path optimization and ship routing. A recent study has confirmed occurrence of extreme waves with a typical significant wave height of up to 30 meters [2]. Using the meteorological and wave models, numerical simulations of the weather and sea state were conducted for eight rough sea cases using the grid point value datasets from NCEP-FNL and ERA-Interim. Model results were validated by shipboard measurements and ship motion calculations. Results show a better performance of NCEP-FNL on generating high ocean surface wind speed of heavy weather than that of the ERA-Interim. On the other hand, the ERA-Interim tends to perform better for prediction of wind direction [3].

Nowadays, the shipping industry is focusing on the reduction of fuel consumption along with the safety of the vessel. To reduce fuel consumption, estimation of resistance/ added resistance due to wave and speed loss during the voyage should be accurate. Therefore, oceanographic parameters, which affect the speed and course keeping, should be accurately considered. The speed of the ship depends on wave height, wave period, wave direction and wind speed and direction [4-7]. Added resistance affects ship's manoeuvring and results in a drop in ship speed. Added resistance, which is the difference between the total resistance in waves and calm water resistance, causes an increase in fuel consumption. Evaluation of increased fuel consumption is made based on estimated added resistance for different speeds and wave frequencies [8]. The concept of EEDI (introduced by IMO), requires the ship designer/ ship builder to calculate the resistance due to waves and wind with reference to resistance in calm water. The resistance due to wave and wind for the KVLCC2 model was calculated experimentally and numerically in four different draft conditions: full load, ballast, and two intermediate conditions between the full load and ballast conditions. This experimental and numerical results for the added resistance were compared for the four draft conditions [9]. A comparison of two methods for added resistance in head waves by the Faltinsen method and the Salvesen method is studied for four different ships: two containerships, a bulk carrier and a ro-ro vessel. Both methods give the added resistance in head seas with similar accuracy in the longer waves region [10]. The additional fuel consumption is approximated in relation to the increased resistance, i.e. the difference between the ship resistance in calm water and resistance while operating in head waves for different Froude numbers [11]. Tank tests in long-crested irregular head waves for VLCC model and PCC model have been conducted, and added resistance in irregular waves has been measured and compared with the estimated results by Newman's approximation [12]. The resistance and propulsion characteristics in regular head waves of KVLCC2 have been predicted utilizing the experimental method [13]. Model of DTMB 5415 is validated for twin propeller twin rudder and wind forces and moments acting on the ship were estimated $[14,15]$. The MMG method was proposed for analysing the steady sailing condition and the course stability of a ship under external disturbances due to wind and waves. The steady sailing conditions and the course stability of a PCC ship are calculated using the proposed MMG method under external disturbances in deep and shallow waters [16]. This paper suggests that MMG model simulates the manoeuvring response of the PCC ship accurately. Hence, the same PCC model is used for our simulation study. Simulation on speed-power relations is 
Numerical simulation of ship navigation

in rough seas based on ECMWF data
Patil Prasad Vinayak, Chelladurai Sree Krishna Prabu, Nagarajan Vishwanath, Sha Om Prakash

performed by a performance prediction method for a tanker. From the simulation, a correction formula for quartering and following waves of the added resistance in waves is suggested, and the effect is studied and validated [17]. A physical modelling method, in which the ship resistance-propeller-engine model is developed by using available ship information and basic hydrodynamics; for the analysis of operational scenarios in realistic environmental conditions in three voyages. The added wave resistance is calculated for different wave angle. The results implies that the resistance of wave for lower wave angle is very less [18]. The collective effects of wind speed, significant wave height, and currents on the vessel routing are evaluated. In addition, the impact of typhoons on vessel navigation is assessed. The drift of the vessel mainly depends on the wind speed [19]. Decrease of the ship speed in real conditions is a consequence of the added resistance due to the impact of weather conditions (waves and wind) and due to aggravated working conditions of the propeller-engine system [20]. A container ship, a car carrier and a bulk carrier are examined and the decrease of ship speed in actual seas are discussed [21]. The higher ship's speed produces more emission. The implications of various maritime emissions reductions policies for maritime logistic are studied [22]. Maki et al. used a real-coded genetic algorithm technique for weather-routing of the ship for the voyage along the great-circle route to avoid maritime accidents due to parametric rolling [23]. Two types of optimized routing strategies, i.e. minimum travel time and minimum fuel consumption, with different constraints, such as land boundaries, significant wave heights, engine revolution speeds and roll responses have been studied [24,25].

In this paper, the analysis of ERA-interim data is carried out. Wave height, wave period, wind speed and wind direction from 1992 to 2018 are studied. Next, the effects of environmental factors (waves, wind) on vessel resistance are calculated. Then the fuel consumption of the vessel on different routes in different weather conditions is evaluated. Furthermore, the PCC and VLCC vessel simulation is validated with engine power and rpm of the actual tanker and PCC ship.

\section{Ocean wind and wave data analysis}

The study of ocean parameters is important for the safe sailing of the vessel. This is because rough weather conditions in the ocean affect the ship's propulsion performance. To confirm the satellite data we do a small exercise. Two examples of damage to the ship are checked. Satellite data is used to gather wave information at the accident site. The first example is the Nakhodka, a Russian oil tanker, that was loaded with 19,000 tonnes of C-type heavy oil. It broke up into sections and submerged off Oki Island, Shimane Prefecture, Japan on $2^{\text {nd }}$ January 1997. The consequent heavy oil spill contaminated the soil and sea near Oki Island. It also adversely affected the ecosystem of the ocean [26,27]. The variation of mean wave height near Oki Island where the accident happened is shown in Fig. 1. The average wave height shown on that day is $7.3 \mathrm{~m}$ and the average wind speed is $16.5 \mathrm{~m} / \mathrm{s}$. The statistical analysis of wave height implies that peak wave heights during the accident could have exceeded $7.3 \mathrm{~m}$. Similarly, statistical analysis of wind speed indicates that peak wind speed during the accident could have exceeded $16.5 \mathrm{~m} / \mathrm{s}$. 


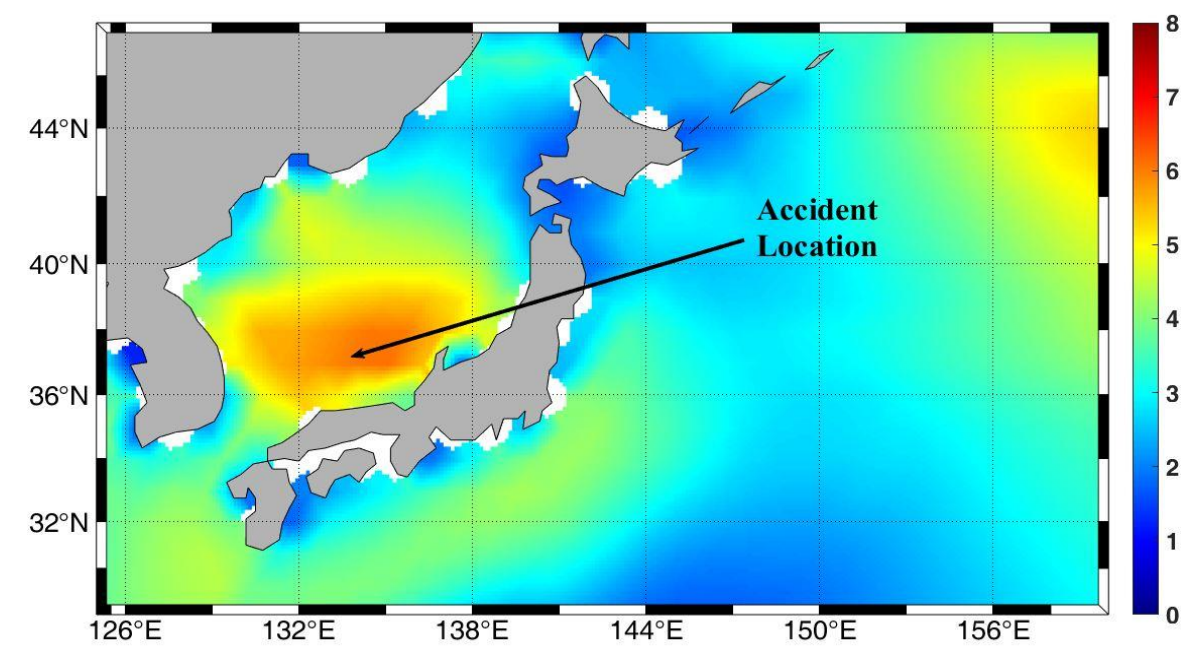

Fig. 1 Variation of mean wave height (in m) at the Oki Island on 2nd January 1997

The second example is that of the merchant ship El Faro which sank east of the Bahamas on $1^{\text {st }}$ October 2015 due to rogue wave conditions during Hurricane Joaquin [28]. The wave height data from 06:00 to 12:00 UTC on $1^{\text {st }}$ October 2015, as recorded by ECMWF satellite data is shown in Fig. 2. In this figure, the area near the Bahamas shows an increase in wave height. The average wave height during 6 hours was observed as $4.78 \mathrm{~m}$. This implies that peak wave heights during the accident could have exceeded $4.78 \mathrm{~m}$. Fedele et al. [28] estimated the probability of El Faro encountering a rogue wave having crest height greater than $14 \mathrm{~m}$ while drifting over a time interval of 10 minutes as $1 / 400$ and over a time interval of 50 minutes as 1/130 respectively. The above two examples show that the wave height, wave period, wave direction, wind speed and wind direction available from satellite data can be reliably used for statistical analysis of safety and route planning of the ships.

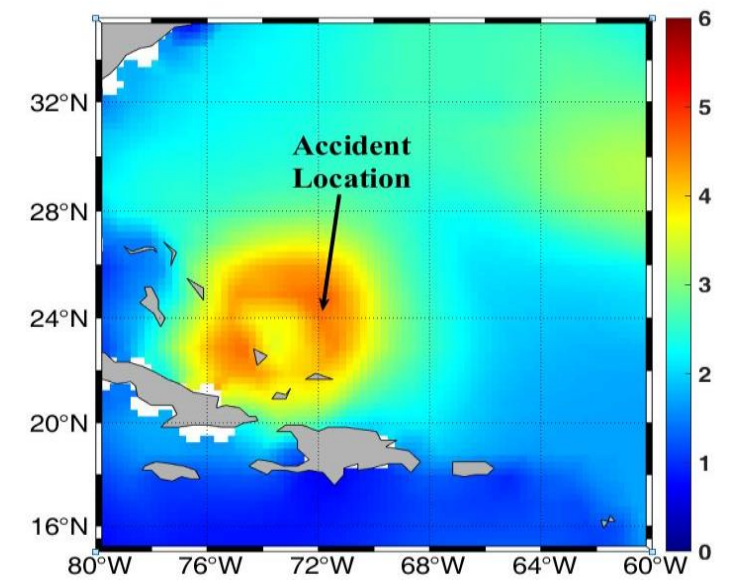

Fig. 2 Variation of mean wave height (in $\mathrm{m}$ ) at the east of the Bahamas on $1^{\text {st }}$ October 2015

Scientists are using oceanographic satellite data for more than 34 years since the launch of GEOSAT in 1985. Following the conclusion of the GEOSAT mission in late 1989, there was a brief interruption until the launch of the ERS-1 satellite in mid-1991. Satellite offers uninterrupted data of wave height and wind speed with world-wide exposure. Such records are being used in a variety of applications like ship routing, offshore engineering design, wind and wave climatology, etc. oceanographic satellites do not directly measure either wave height or wind speed. They measure properties of the water surface, which consequently, after post-processing, gives either wave height or wind speed. Altimeters, radiometers, scatterometers, and synthetic aperture radars are the main four instruments that provide global 
Numerical simulation of ship navigation

in rough seas based on ECMWF data
Patil Prasad Vinayak, Chelladurai Sree Krishna Prabu, Nagarajan Vishwanath, Sha Om Prakash

wave height and wind speed. Out of these instruments, the radar altimeter gives the long duration dataset. ECMWF produces a third-generation global reanalysis of meteorological observations, known as ERA-Interim. ERA-Interim is a global atmospheric reanalysis from 1979. The model data is archived at six hour intervals with $0.75^{\circ}$ spatial resolution. Voluntarily observing vessels, buoys, and satellite scatterometers give the ocean wind speed dataset. Satellite altimeter wave heights were also considered since 1991. ERA-Interim provides superior data than buoy observations [29-33].

The dataset for the significant wave height, mean wave period, wind speed, wave direction from 1992 to 2018 is downloaded from ECMWF with $1^{\circ}$ spatial resolution in netCDF format. Uninterrupted satellite data is available from 1992 to 2018. This paper shows the changes in oceanographic parameters in the first and last ten years and all 27 years. Hence, analysis is done from 1992 to 2001, from 2009 to 2018 and from 1992 to 2018. The ocean region is divided as per the seasonal zone specified in loadline regulations [34]. Mean and variances are calculated for the wave height, wave period, wave direction and wind speed. The season (summer or winter) is defined with respect to the northern hemisphere. Therefore "summer" means "summer" in the Northern Hemisphere and "winter" in the Southern Hemisphere. The mean is calculated for summer and winter zone separately. This is done based on the calendar dates specified in the loadline regulation. CDO software is used for calculating mean and variance of weather parameters. CDO is a command-line suite for manipulating and analysing climate data. CDO is used for calculating the mean and variances of netCDF files.

The resultant wind speed is analysed from wind speed $U_{10}$ and $V_{10}$. Wind speed is given at a height of $10 \mathrm{~m}$ from the surface. Also, the direction of the wind is analysed for each zone and each season. Resultant wind speed and wind angle are calculated as shown in Eqs. 1 and 2 .

$$
\begin{aligned}
& U_{w}=\sqrt{U_{10}{ }^{2}+V_{10}{ }^{2}} \\
& \psi_{w}=\tan ^{-1}\left(U_{10} / V_{10}\right)
\end{aligned}
$$

The load line rules considered in this paper are for vessels having a length of more than $100 \mathrm{~m}$. Furthermore, the mean and variances of $\mathrm{H}_{1 / 3}$, MWP, wind speed, wind direction and wave direction of loadline zones as per season is evaluated. The purpose of loadline rules is to ensure that a ship has sufficient freeboard, adequate reserve buoyancy and bow height [34]. The necessity for minimum freeboard and bow height is to ensure that heavy seas do not capsize/ damage the ship or floating offshore structure. The loadline chart represents the seasonal zones, areas, and periods in a particular sea area at a given time of the year. In Fig. 3 , the international loadline zones and seasons are shown. Loadline rules suggest that the tropical zone is the safest zone for a ship or floating offshore structure. In addition, it shows that the winter zone is dangerous for a ship or floating offshore structure. In this analysis, zones are divided into summer, winter, and tropical. Seasonal zones are either combined with winter or summer zone based on the season of a voyage as shown in Appendix A. Therefore, in winter analysis, zones considered for analysis are winter and tropical. Similarly, in summer analysis, zones considered for analysis are summer and tropical. Occasionally sudden changes in the pattern of wave height, wave period or wind speed can be observed in the figures. This is due to the loadline zone boundary. Across a seasonal zone boundary, the calendar months for which averaging are carried out are different. 


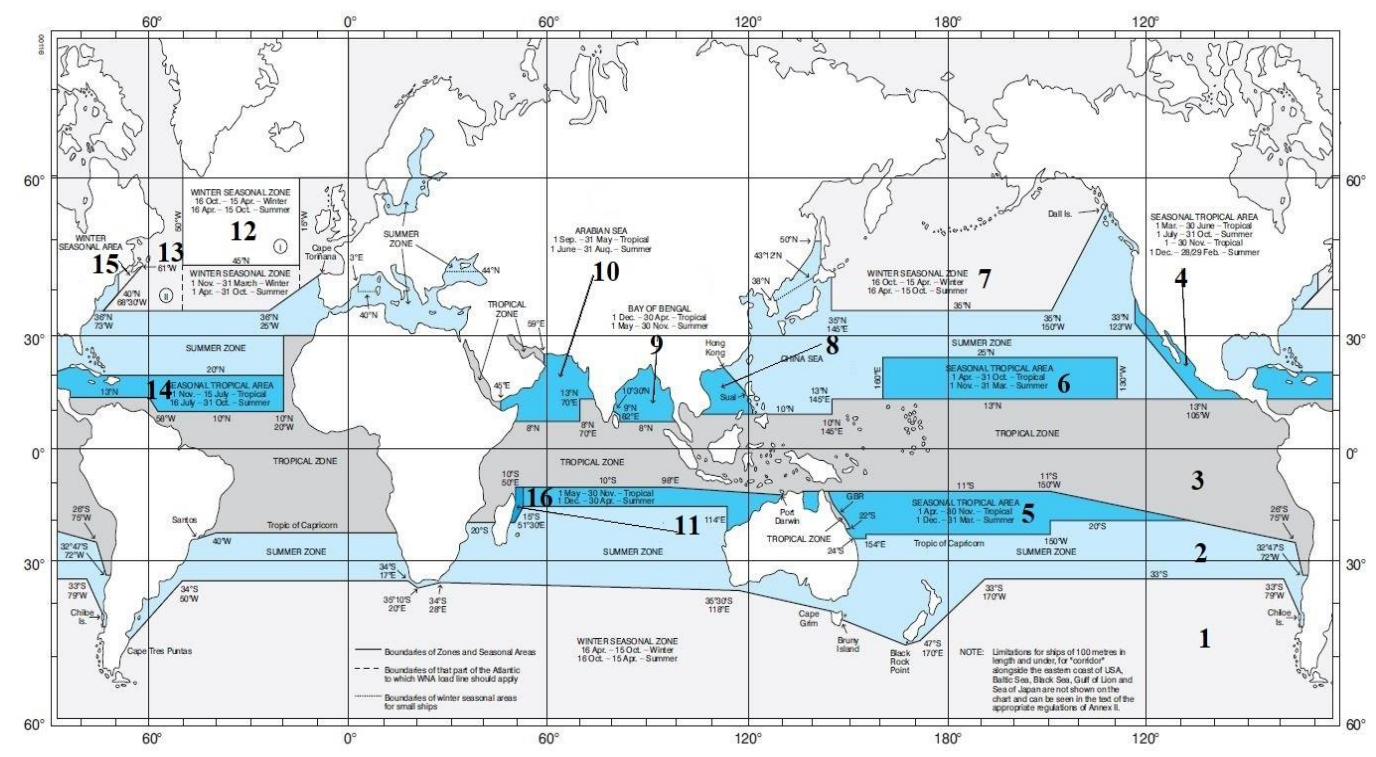

Fig. 3 International Loadline Zones and Areas Map [34]

The mean of "significant wave height", "mean wave period", "wind speed" and "wind direction" is shown in Figs. $4 \sim 7$. The term 'mean' in Figs. $4 \sim 7$ implies, mean of a weather parameter for 10 years (1992 to 2001 or 2009 to 2018 ) or 27 years (1992 to 2018 ). In Fig. 4, the mean of significant wave height of winter and summer zones for the years 1992 to 2001, 2009 to 2018 and 1992 to 2018 is presented. It shows that wave heights in the recent decade have increased in the Southern Ocean and more ice near Antarctica has melted in recent years as compared to 1992. Generally, wave heights are higher in the Southern Ocean, North Atlantic Ocean and North Pacific Ocean. In Fig. 5, the mean wave period for summer and winter for 1992 to 2001, 2009 to 2018 and 1992 to 2018 is shown. MWP is less near to land and the polar region as shown in Fig. 5. Overall, mean wave period decreased in the period 2009 to 2018 as compared to the period 1992 to 2001. In Fig. 6, the mean wind speed of 10 years for summer and winter from 1992 to 2001, 2009 to 2018 and the mean wind speed of 27 years for summer and winter from 1992 to 2018 are shown. It implies that wind speed has increased in the Southern Ocean and North Atlantic Ocean region. The wind direction of winter and summer zones for the period 1992 to 2001, 2009 to 2018 and 1992 to 2018 is illustrated in Fig. 7. This figure is shown in the colour instead of the arrow because the data downloaded is of $1^{\circ}$ spatial resolution and hence these arrows will be very small. The variance of significant wave height for winter and summer zones for the period 1992 to 2001 and 2009 to 2018 is shown in Fig. 8. It can be observed that variance is more in the Southern Ocean, North Atlantic Ocean region and North Pacific Ocean region. In Fig. 9, the variance of the wave period for summer and winter seasons for the periods 1992 to 2001 and 2009 to 2018 is shown. The variance is more near to the coastal area. Figures $8 \sim 10$ shows that the 27-year variance is greater than both the first 10-year (1992 - 2001) variance and the last 10year (2009 - 2018) variance. This shows that the change in wave height, wave period and wind speed in recent years as compared to previous years is significantly high. The variance of wind speed for winter and summer seasons for the periods 1992 to 2001 and 2009 to 2018 is shown in Fig. 10. The variance of wind speed is different for the summer and winter seasons. The variance is more towards the poles and less in the tropical zone. This is important because in some wind spectrum model, variance needs to be input for calculating the gust wind. A higher variance will mean higher peaks in the time series of gust wind. However, higher variance in case of wave height and wave period will mean new wave spectrum model needs to be developed. 
Numerical simulation of ship navigation in rough seas based on ECMWF data
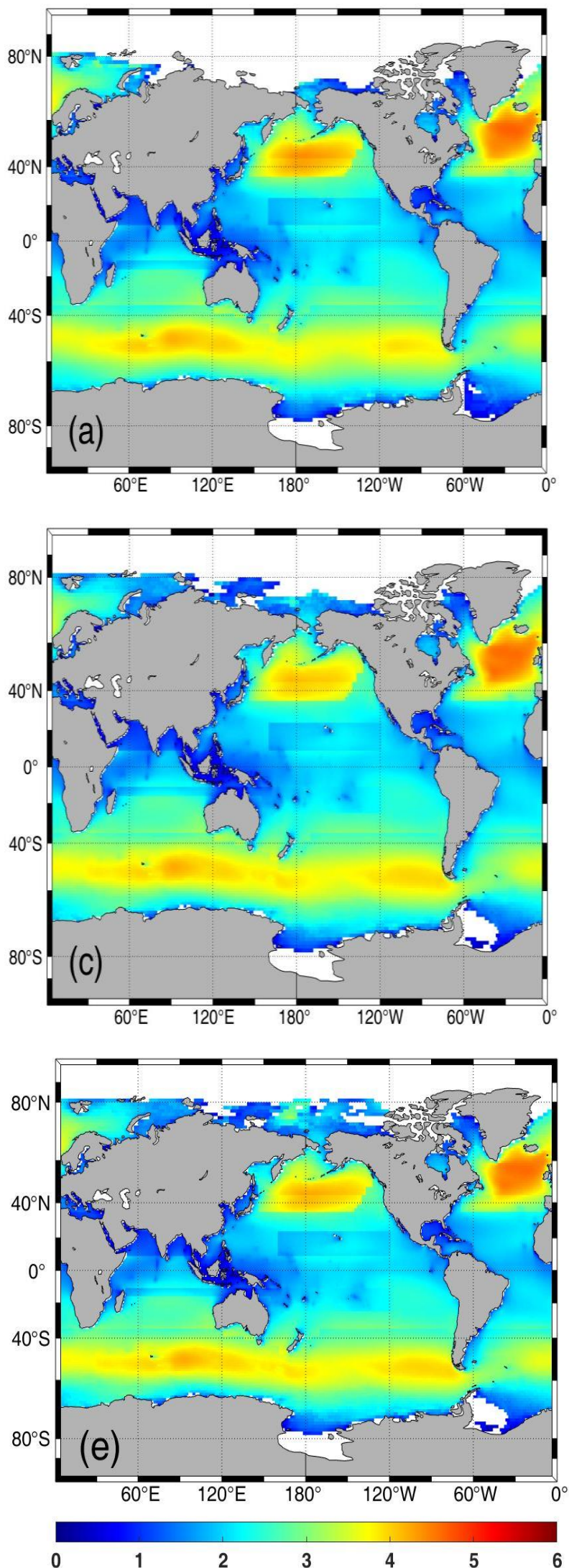

Patil Prasad Vinayak,

Chelladurai Sree Krishna Prabu,

Nagarajan Vishwanath, Sha Om Prakash
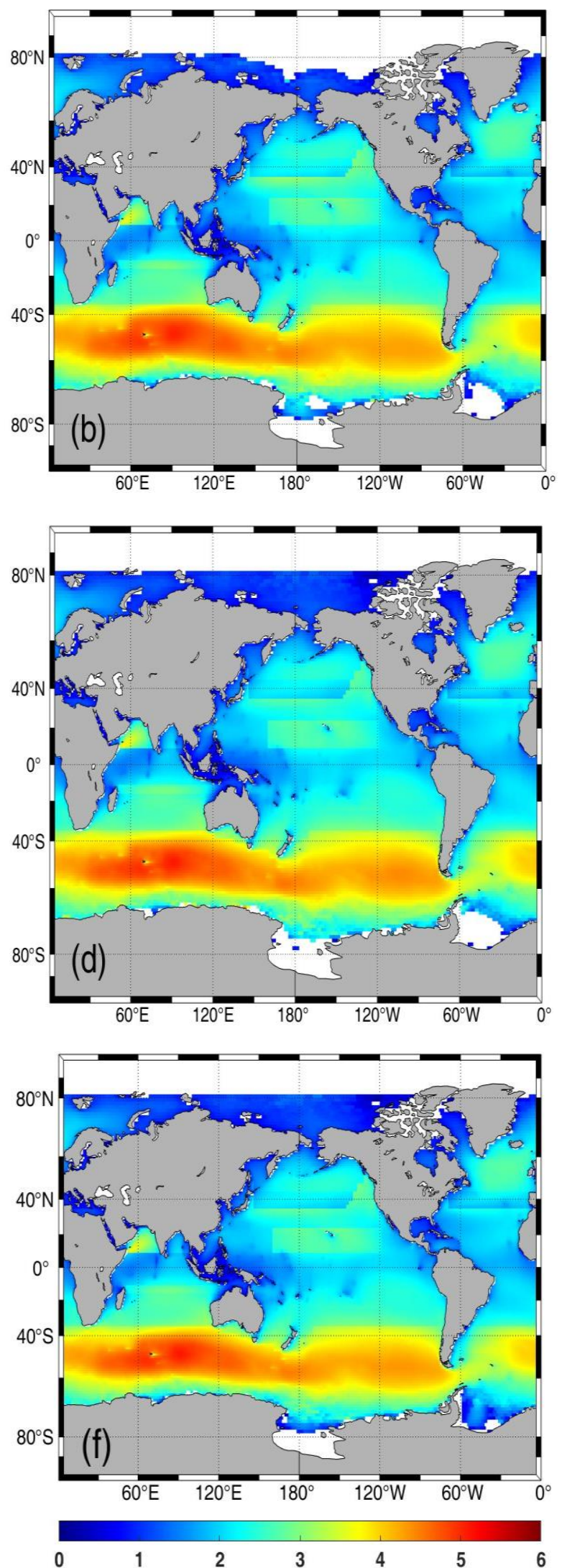

Fig. 4 Mean of significant wave height (in m) around Earth's surface (a) 1992 - 2001 Winter (b) 1992 - 2001 Summer (c) 2009 - 2018 Winter (d) 2009 - 2018 Summer (e) 1992 - 2018 Winter (f) 1992 - 2018 Summer. 
Patil Prasad Vinayak,

Chelladurai Sree Krishna Prabu,

Nagarajan Vishwanath, Sha Om Prakash
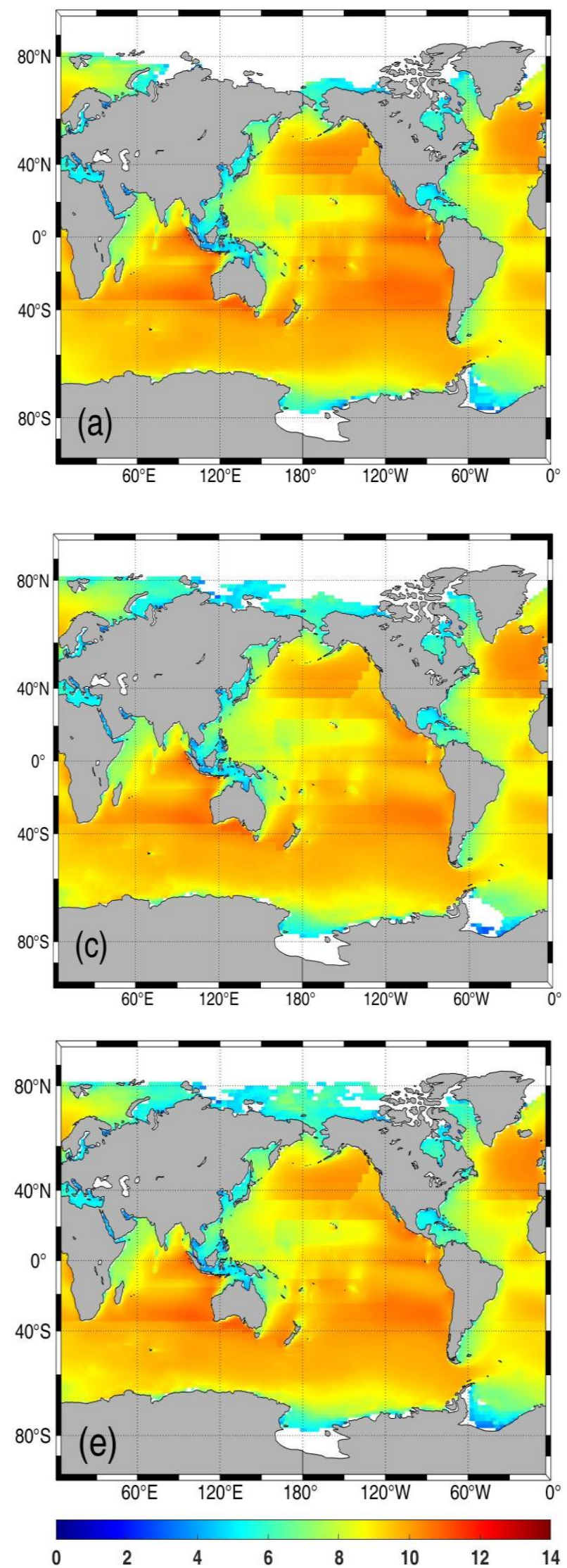

Numerical simulation of ship navigation in rough seas based on ECMWF data
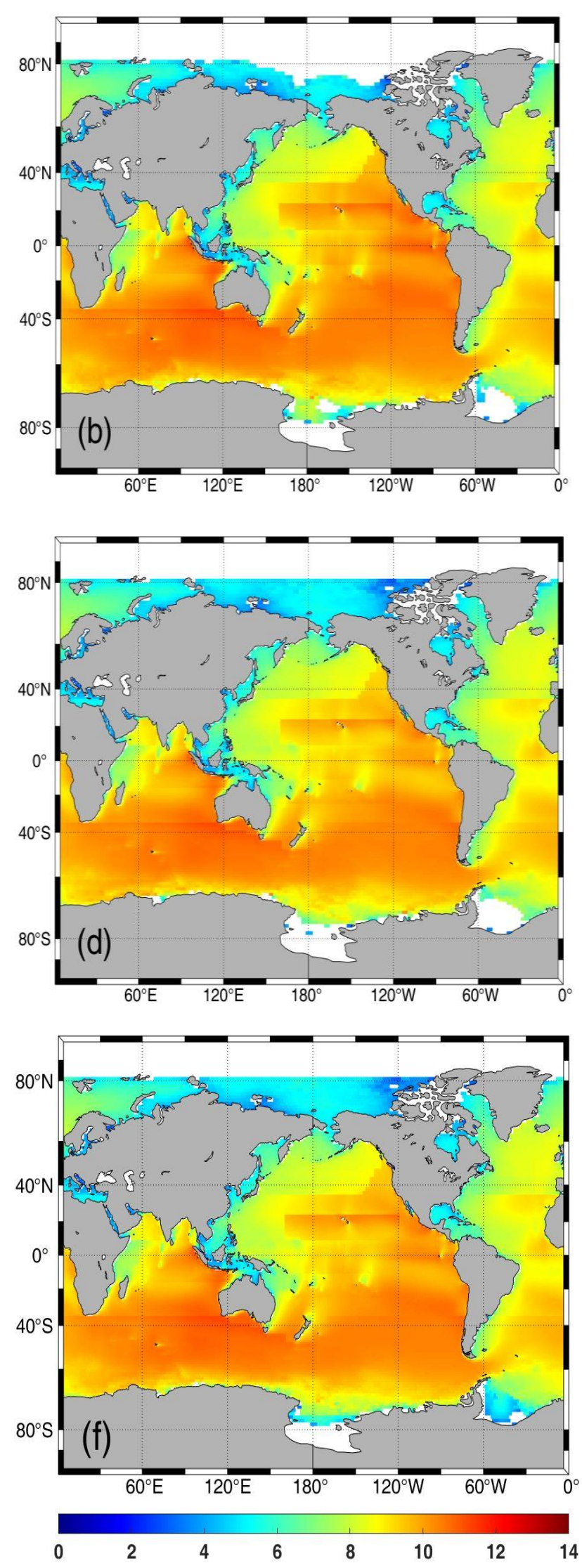

Fig. 5 Mean wave period (in sec) around the Earth's surface (a) 1992 - 2001 Winter (b) 1992 - 2001 Summer (c) 2009 - 2018 Winter (d) 2009 - 2018 Summer (e) 1992 - 2018 Winter (f) 1992 - 2018 Summer 
Numerical simulation of ship navigation in rough seas based on ECMWF data
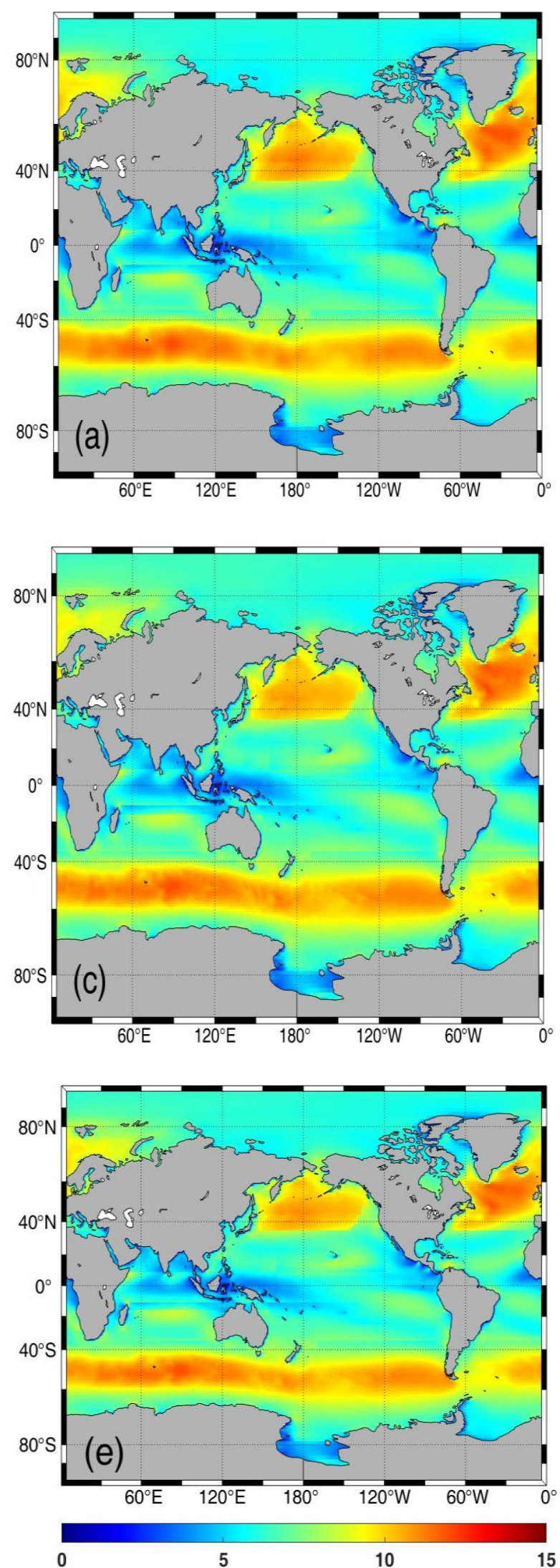

Patil Prasad Vinayak,

Chelladurai Sree Krishna Prabu, Nagarajan Vishwanath, Sha Om Prakash
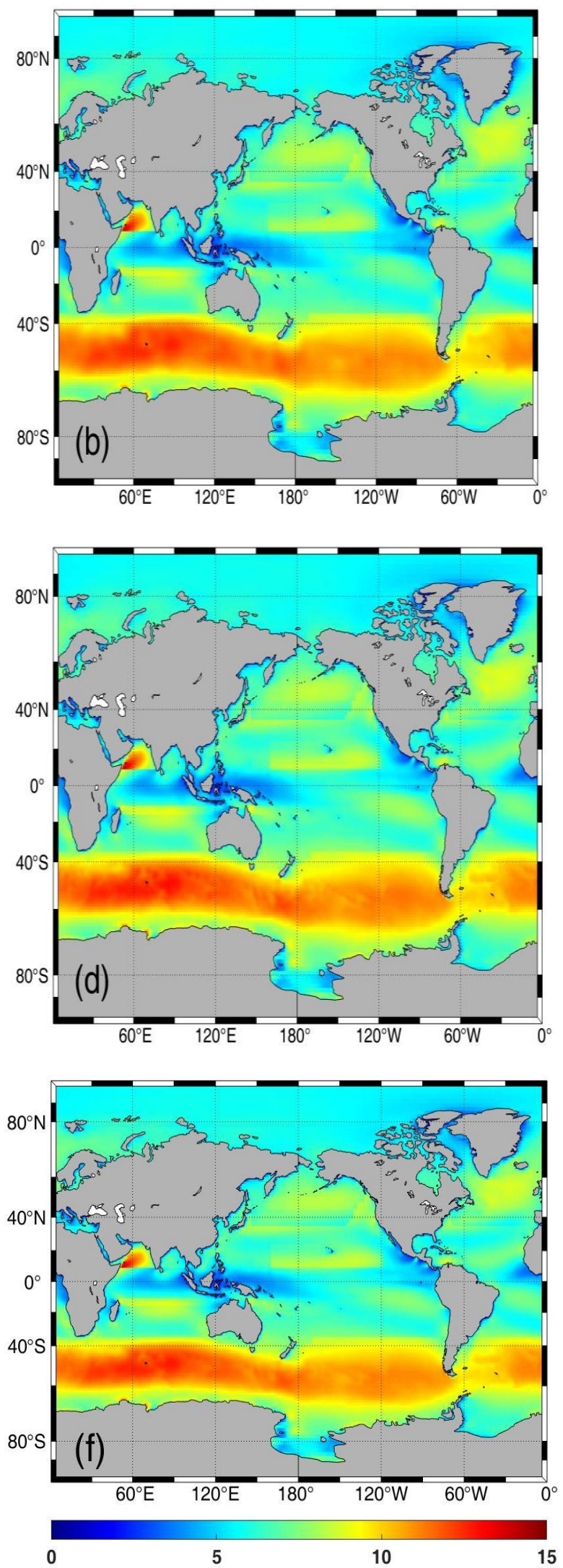

Fig. 6 Mean wind speed (in m/s) around the Earth's surface (a) 1992 - 2001 Winter (b) 1992 - 2001 Summer (c) 2009 - 2018 Winter (d) 2009 - 2018 Summer (e) 1992 - 2018 Winter (f) 1992 - 2018 Summer 
Patil Prasad Vinayak,

Chelladurai Sree Krishna Prabu,

Nagarajan Vishwanath, Sha Om Prakash
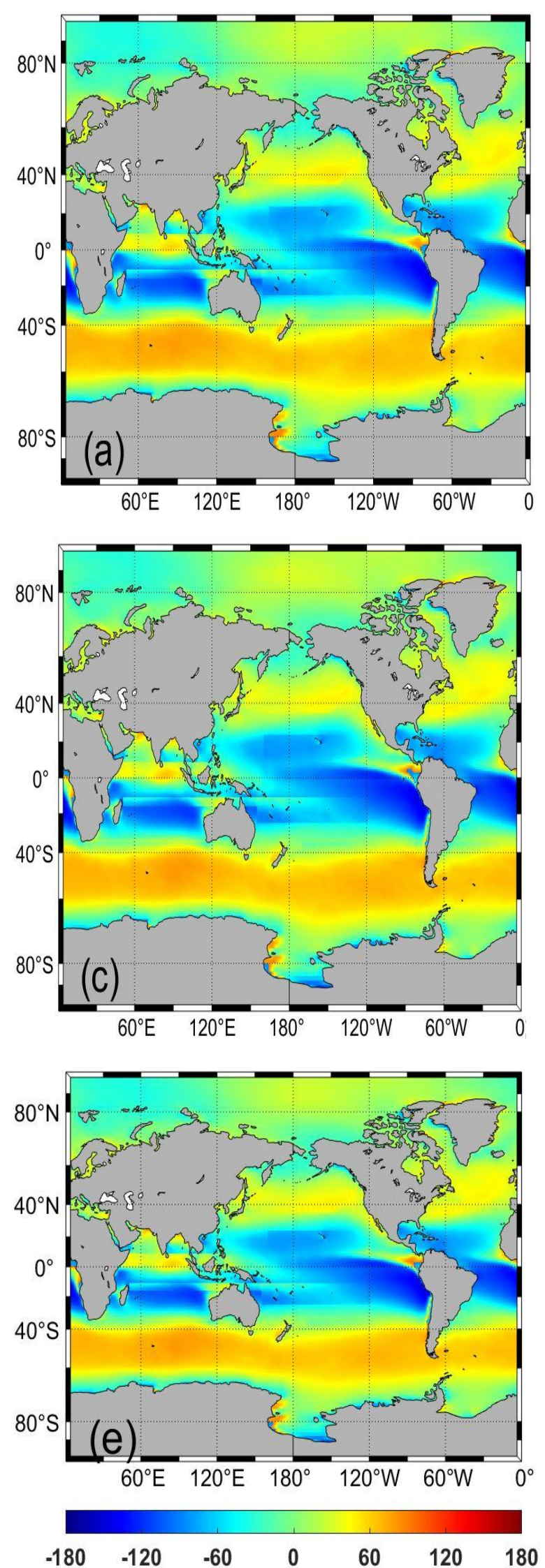

Numerical simulation of ship navigation in rough seas based on ECMWF data
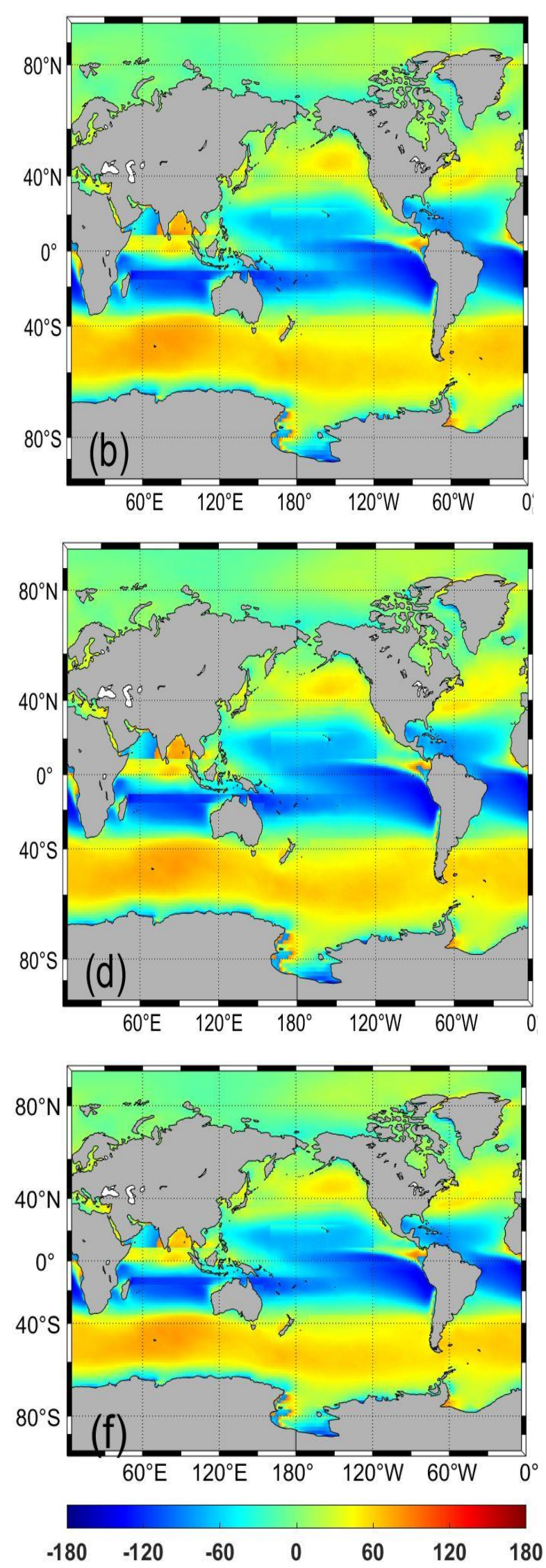

Fig. 7 Mean wind direction (in degree) around the Earth's surface (a) 1992 - 2001 Winter (b) 1992 - 2001 Summer (c) 2009 - 2018 Winter (d) 2009 - 2018 Summer (e) 1992 - 2018 Winter (f) 1992 - 2018 Summer 
Numerical simulation of ship navigation in rough seas based on ECMWF data
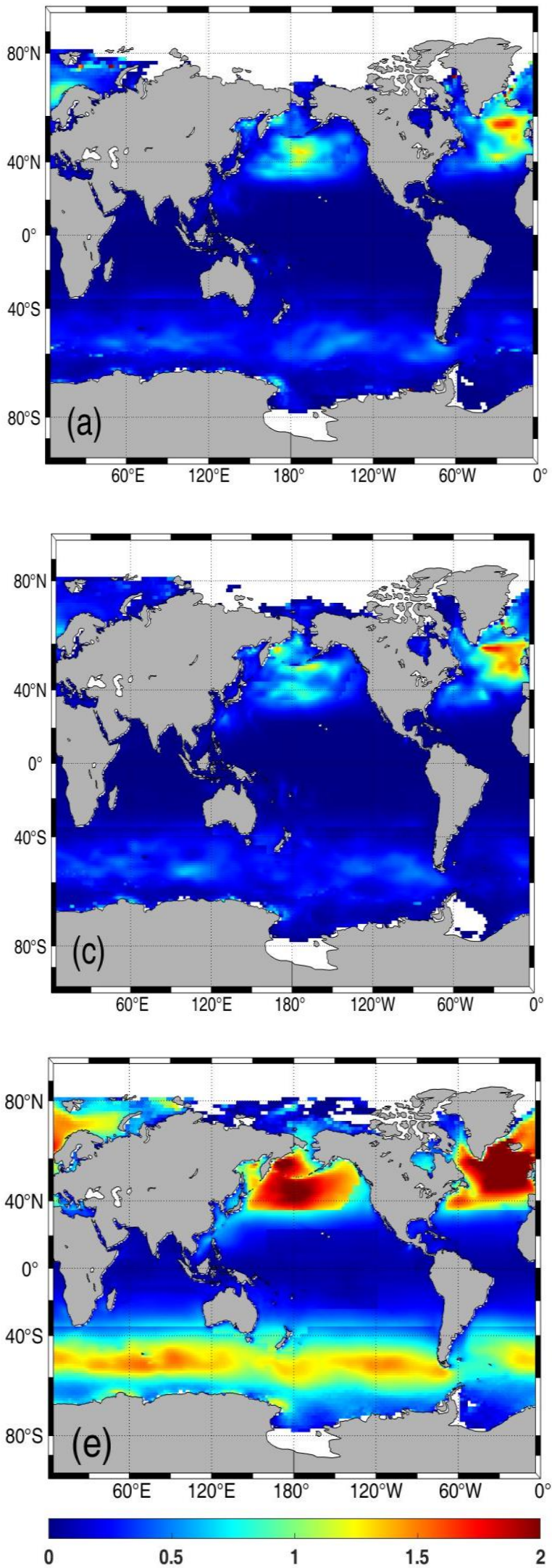

Patil Prasad Vinayak,

Chelladurai Sree Krishna Prabu, Nagarajan Vishwanath, Sha Om Prakash
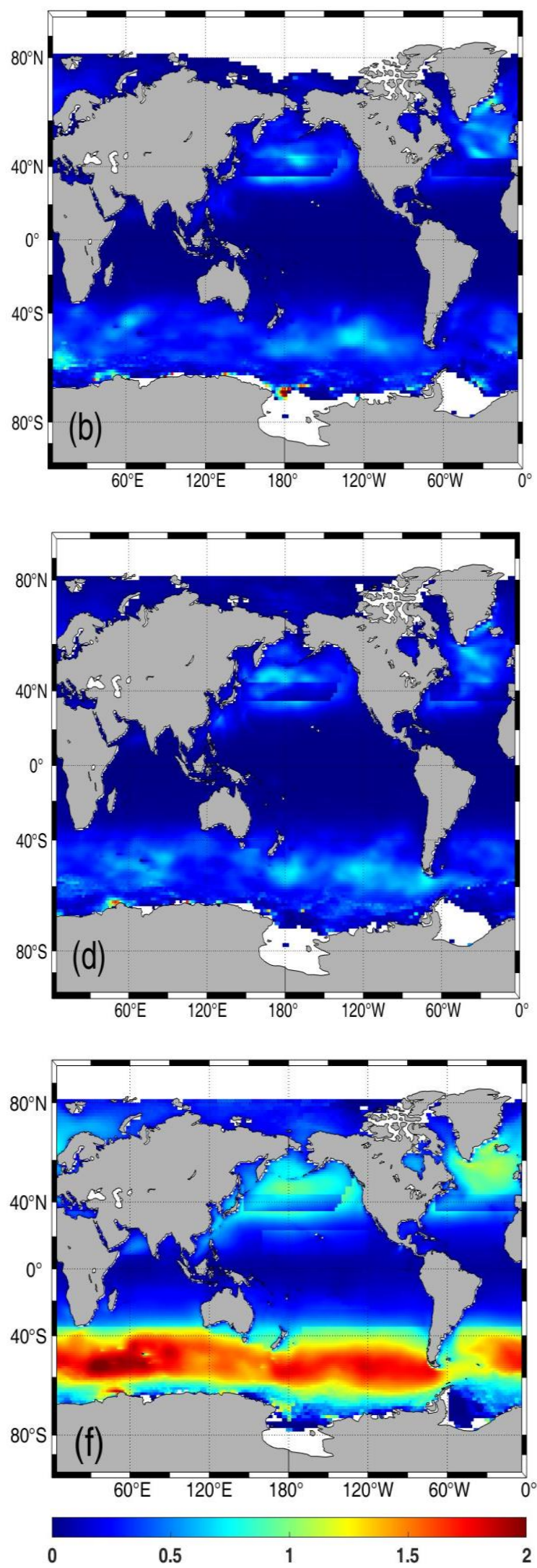

Fig. 8 Variance of significant wave height (in $\mathrm{m}^{2}$ ) along Earth's surface. (a) 1992 - 2001 Winter (b) 1992 2001 Summer (c) 2009 - 2018 Winter (d) 2009 - 2018 Summer (e) 1992 - 2018 Winter (f) 1992 - 2018 Summer 
Patil Prasad Vinayak,

Chelladurai Sree Krishna Prabu,

Nagarajan Vishwanath, Sha Om Prakash
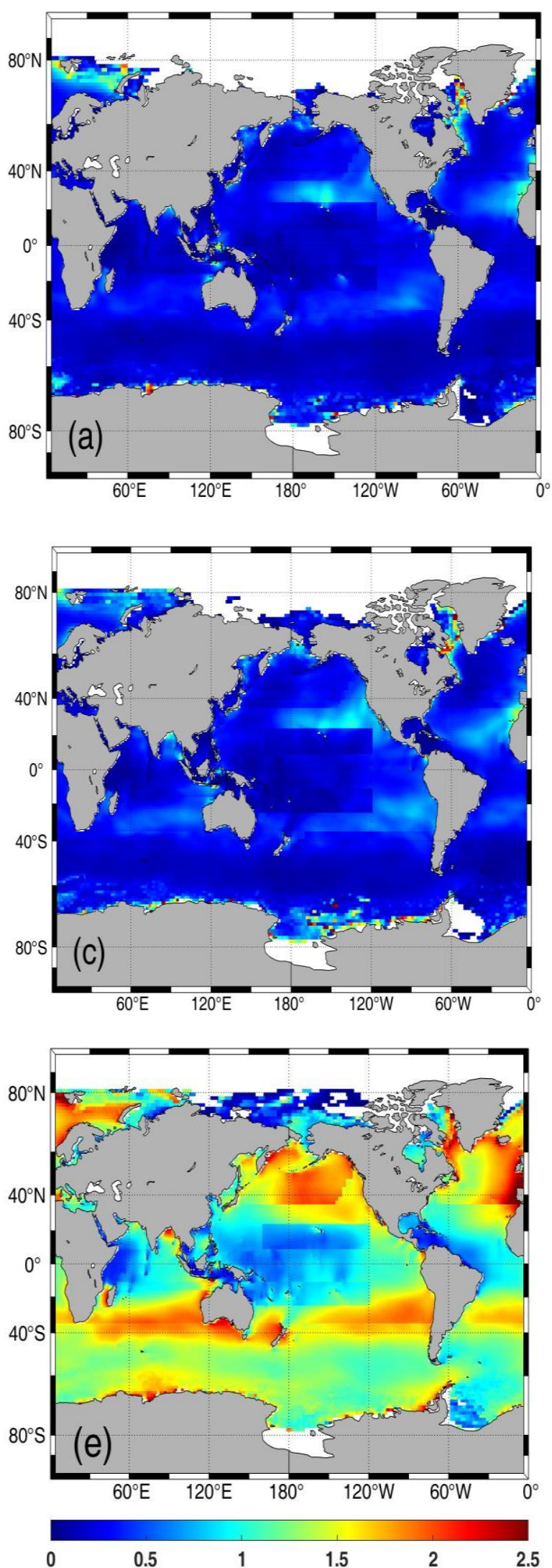

Numerical simulation of ship navigation in rough seas based on ECMWF data
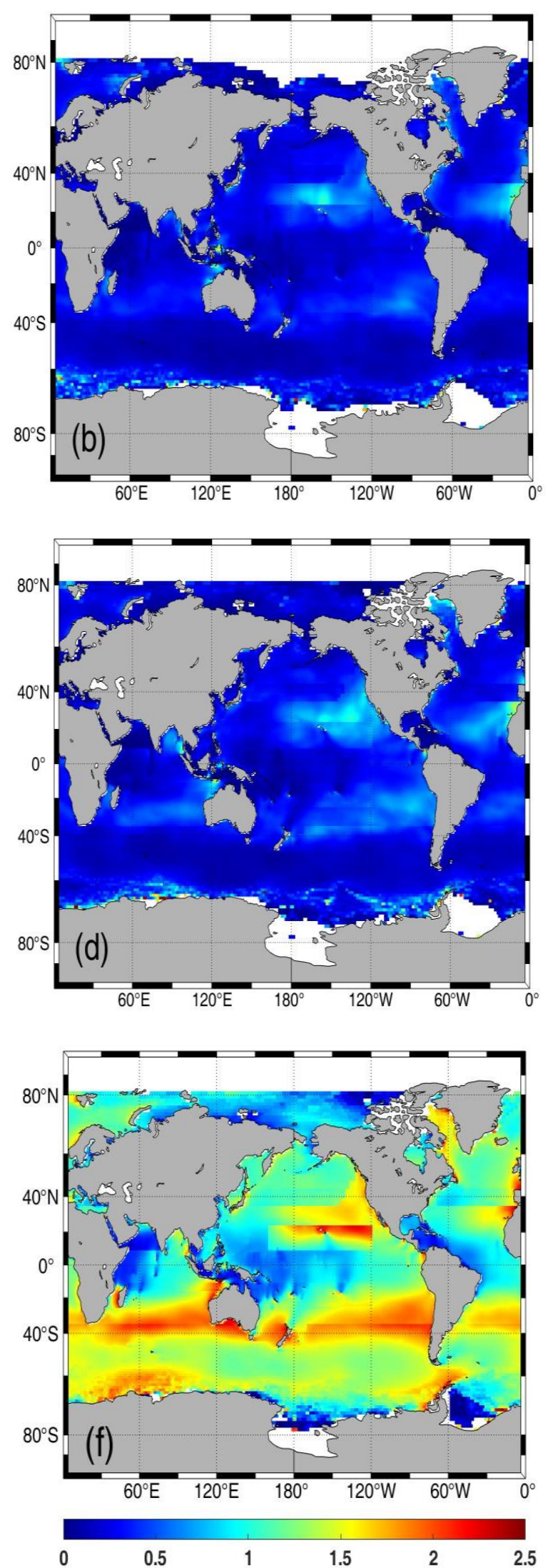

Fig. 9 Variance of mean wave period (in $\mathrm{sec}^{2}$ ) along Earth's surface. (a) 1992 - 2001 Winter (b) 1992 - 2001 Summer (c) 2009 - 2018 Winter (d) 2009 - 2018 Summer (e) 1992 - 2018 Winter (f) 1992 - 2018 Summer 
Numerical simulation of ship navigation in rough seas based on ECMWF data
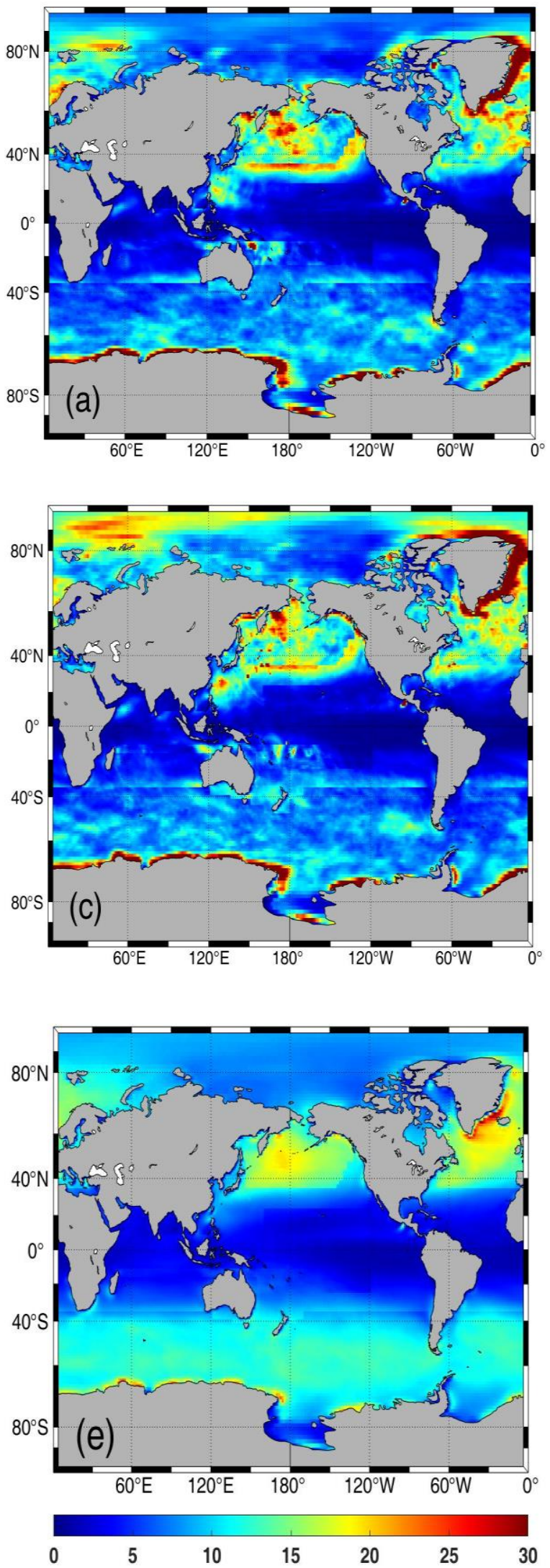

Patil Prasad Vinayak,

Chelladurai Sree Krishna Prabu, Nagarajan Vishwanath, Sha Om Prakash
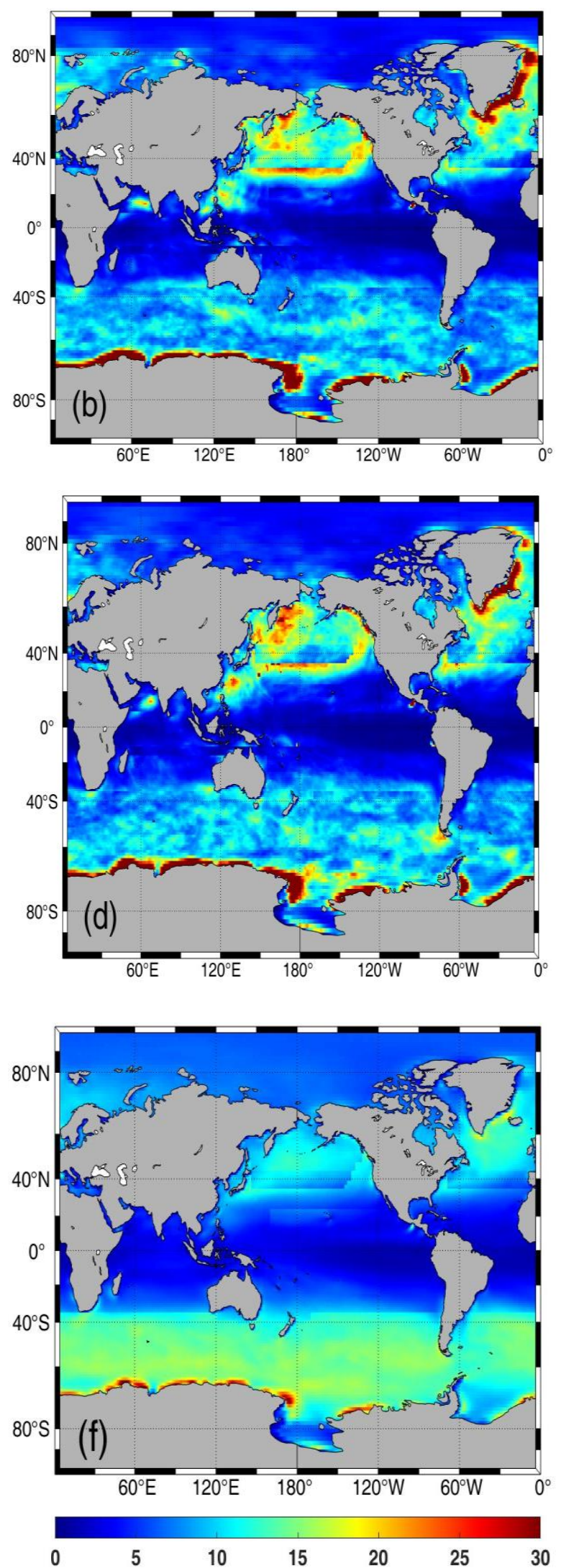

Fig. 10 Variance of wind speed $\left(\mathrm{m}^{2} / \mathrm{s}^{4}\right)$ along Earth's surface. (a) 1992 - 2001 winter (b) 1992 - 2001 summer (c) 2009 - 2018 winter (d) 2009 - 2018 summer (e) 1992 - 2018 winter (f) 1992 - 2018 summer 
Patil Prasad Vinayak,

Chelladurai Sree Krishna Prabu,

Nagarajan Vishwanath, Sha Om Prakash
Numerical simulation of ship navigation in rough seas based on ECMWF data

\section{Manoeuvring mathematical model of ships}

MMG type manoeuvring mathematical model of a ship is used for the simulation. To see the influence of the environmental condition on the ship type and size, three different ship types are used for simulation. The ship types DTMB 5415 [14], PCC [35] and VLCC [36] are used for simulation. The VLCC [17] model is selected to match the dimensions of recent commercial VLCC ship designs. DTMB 5415 ship has twin-propeller twin rudder system while the PCC and VLCC ships have single propeller single rudder system. The full-scale particulars of the three-ship types are shown in Table 1.

Table 1 Principal particulars of the DTMB 5415, PCC and VLCC ships

\begin{tabular}{|c|c|c|c|}
\hline Particular & DTMB 5415 & PCC & VLCC \\
\hline$L_{O A}(\mathrm{~m})$ & 153.3 & 200 & 333 \\
\hline$L_{P P}(\mathrm{~m})$ & 142.0 & 190.0 & 319.0 \\
\hline$B_{W L}(\mathrm{~m})$ & 19.06 & 32.20 & 60.0 \\
\hline$T(\mathrm{~m})$ & 6.15 & 8.20 & 21 \\
\hline$C_{B}$ & 0.507 & 0.547 & 0.817 \\
\hline$m^{\prime}$ & 0.1361 & 0.1854 & 0.3073 \\
\hline$I_{z z}{ }^{\prime}$ & 0.0085 & 0.0116 & 0.0192 \\
\hline$J_{z z}$ & 0.0072 & 0.0098 & 0.0163 \\
\hline$I_{p p}\left(\mathrm{~kg} \cdot \mathrm{m}^{2}\right)$ & 26414 & 40535 & 300234 \\
\hline$J_{p p}\left(\mathrm{~kg} \cdot \mathrm{m}^{2}\right)$ & 6604 & 10134 & 75058 \\
\hline$S_{B H}\left(\mathrm{~m}^{2}\right)$ & 2972 & 5051 & 26583 \\
\hline$D_{P}(\mathrm{~m})$ & 6.15 & 6.7 & 10 \\
\hline$A_{T}\left(\mathrm{~m}^{2}\right)$ & 368.36 & 1044.75 & 1209 \\
\hline$A_{L}\left(\mathrm{~m}^{2}\right)$ & 1143.43 & 5971.49 & 4520 \\
\hline Design Speed (knots) & 18 & 20 & 15.7 \\
\hline$C_{1}$ & 1 & 2 & 1.8 \\
\hline$C_{2}$ & 1 & 5 & 0.1 \\
\hline
\end{tabular}

The coordinate system is shown in Fig. 11. The MMG type 4 DoF model used for representing the ship's manoeuvring motions [14] is shown in Eq. 3.

$$
\left.\begin{array}{l}
\left(m+m_{x}\right) \dot{u}-\left(m+m_{y}\right) r v-m x_{G} r^{2}+m x_{G} p r=X_{H}+X_{P}+X_{R}+X_{W}+X_{A W} \\
\left(m+m_{x}\right) \dot{v}+\left(m+m_{x}\right) u r-m z_{G} p+\left(m x_{G}-Y_{\dot{r}}\right) \dot{r}=Y_{H}+Y_{R}+Y_{W}+Y_{A W} \\
\left(I_{z}+J_{z}\right) \dot{r}+\left(m x_{G}-N_{\dot{v}}\right) \dot{v}+m x_{G} u r=N_{H}+N_{P}+N_{R}+N_{W} \\
\left(I_{x}+J_{x}\right) \dot{p}-\left(m z_{G}+K_{\dot{v}}\right) \dot{v}-K_{\dot{r}} \dot{r}-K_{\dot{\phi}} p-m z_{G} u r=K_{H}+K_{R}+K_{W}
\end{array}\right\}
$$




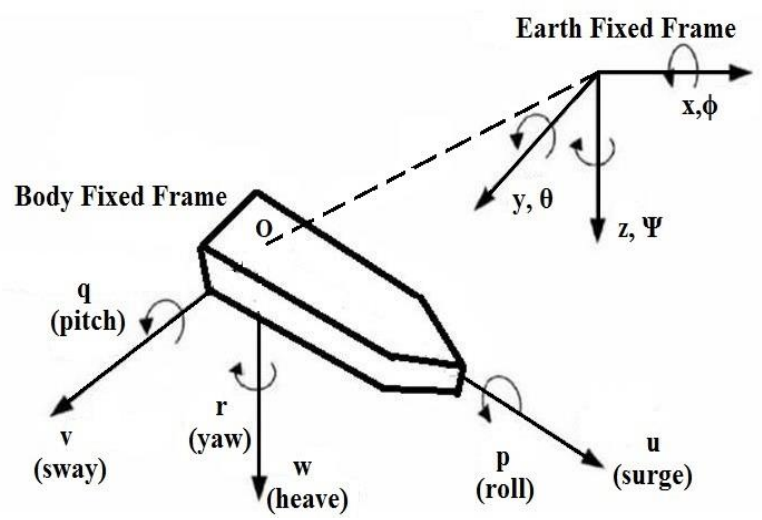

Fig. 11 The coordinate system for ship motions

The 4 DoF considers surge, sway, roll and yaw motions while the 3 DoF considers surge, sway and yaw motion. For all the simulations, the pitch and heave motion components are ignored. The body plan of ships used for simulation is shown in Fig. 12. The hydrodynamic hull force model for the DTMB 5415 ship [14] is shown in Eq. 4, PCC ship [35] is shown in Eq. 5 and VLCC ship [36] is shown in Eq. 6.

$$
\begin{aligned}
& X_{H}=X_{*}+X_{v v} v^{2}+X_{r r} r^{2}+X_{\phi \phi} \phi^{2}+X_{\dot{u}} \dot{u} \\
& Y_{H}=Y_{v} v+Y_{v v v} v^{3}+Y_{r} r+Y_{r r r} r^{3}+Y_{v v r} v^{2} r+Y_{v v r} v r^{2}+Y_{\phi} \phi+Y_{\phi \phi \phi} \phi^{3}+Y_{v v \phi} v^{2} \phi \\
& +Y_{v \phi \phi} \nu \phi^{2}+Y_{r r \phi} r^{2} \phi+Y_{r \phi \phi} r \phi^{2}+Y_{\dot{v}} \dot{v}+Y_{\dot{r}} \dot{r}+Y_{\dot{p}} \dot{p} \\
& N_{H}=N_{v} v+N_{v v v} v^{3}+N_{r} r+N_{r r r} r^{3}+N_{v v r} v^{2} r+\mathrm{N}_{v v r} v r^{2}+N_{\phi} \phi+N_{\phi \phi \phi} \phi^{3}+N_{v v \phi} v^{2} \phi \\
& +N_{\nu \phi \phi} v \phi^{2}+N_{r r \phi} r^{2} \phi+N_{r \phi \phi} r \phi^{2}+N_{\dot{v}} \dot{v}+N_{\dot{r}} \dot{r} \\
& K_{H}=-m g G Z^{\prime}-z_{H} Y_{H}(v, r)+K_{\phi} \phi+K_{\phi \phi \phi} \phi^{3}+K_{v v \phi} v^{2} \phi+K_{v \phi \phi} v \phi^{2}+K_{r r \phi} r^{2} \phi \\
& +K_{r \phi \phi} r \phi^{2}+K_{\dot{v}} \dot{v}+K_{\dot{r}} \dot{r}+K_{p} p+K_{\dot{p}} \dot{p} \\
& X_{H}^{\prime}=X_{0}^{\prime}+X_{\beta \beta}^{\prime} \beta^{2}+\left(X_{\beta r}^{\prime}-m_{y}^{\prime}\right) \beta r^{\prime}+X_{r r}^{\prime} r^{\prime 2}+X_{\beta \beta \beta \beta}^{\prime} \beta^{4}+X_{\beta \beta \beta r}^{\prime} \beta^{3} r^{\prime} \\
& Y_{H P}^{\prime}=Y_{\beta}^{\prime} \beta+\left(Y_{r}^{\prime}-m_{x}^{\prime}\right) r^{\prime}+Y_{\beta \beta \beta}^{\prime} \beta^{3}+Y_{r r r}^{\prime} r^{\prime 3}+\left(Y_{\beta \beta r}^{\prime} \beta+Y_{\beta r r}^{\prime} r^{\prime}\right) \beta r \\
& N_{H}^{\prime}=N_{\beta}^{\prime} \beta+N_{r}^{\prime} r^{\prime}+N_{\beta \beta \beta}^{\prime} \beta^{3}+N_{r r r}^{\prime} r^{\prime 3}+\left(N_{\beta \beta r}^{\prime} \beta+N_{\beta r r}^{\prime} r^{\prime}\right) \beta r \\
& X_{H}^{\prime}=X_{v r}^{\prime} v^{\prime} r^{\prime}+X_{0}^{\prime} \\
& Y_{H}^{\prime}=Y_{\beta}^{\prime} \beta+Y_{r}^{\prime} r^{\prime}+Y_{\beta \beta}^{\prime} \beta|\beta|+Y_{r r}^{\prime} r^{\prime}\left|r^{\prime}\right|+\left(Y_{\beta \beta r}^{\prime} \beta+Y_{\beta r r}^{\prime} r^{\prime}\right) \beta r \\
& N_{H}^{\prime}=N_{\beta}^{\prime} \beta+N_{r}^{\prime} r^{\prime}+N_{\beta \beta}^{\prime} \beta|\beta|+N_{r r}^{\prime} r^{\prime}\left|r^{\prime}\right|+\left(N_{\beta \beta r}^{\prime} \beta+N_{\beta r r}^{\prime} r^{\prime}\right) \beta r^{\prime}
\end{aligned}
$$




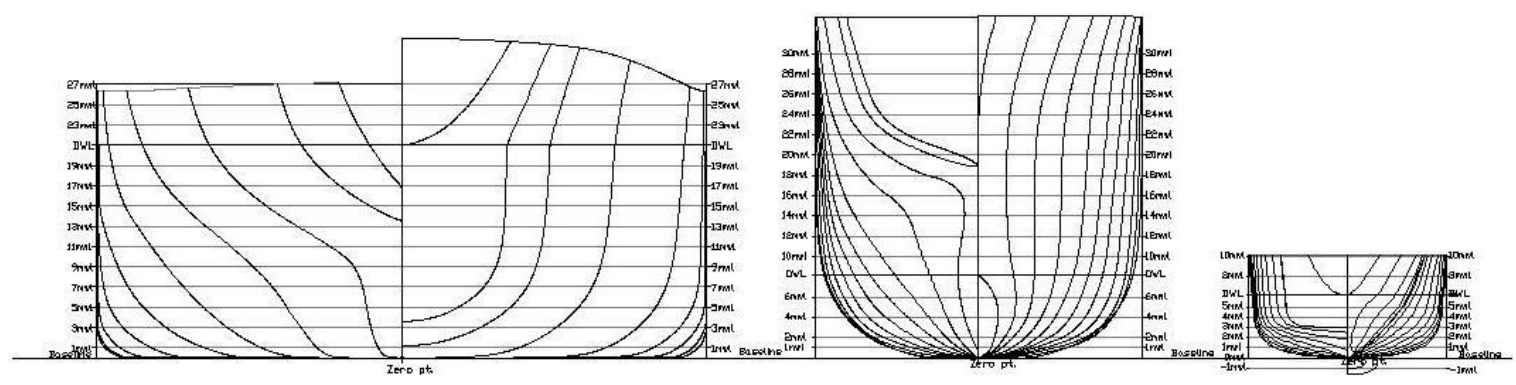

Fig. 12 Body plan of VLCC (left), PCC (middle) and DTMB 5415 (right) ship models

The rudder model is shown in Eq. 7. The rudder model shown is for twin-propeller twin rudder system. For single propeller single rudder system, the subscripts $\{S, P\}$ will be deleted.

$$
\left.\begin{array}{rl}
X_{R}= & -\left(1-t_{R\{P}^{S S}\right)\left(F_{R Y\{S\}} \sin \delta+F_{R X\{S\}} \cos \delta+F_{R Y\{P\}} \sin \delta+F_{R X\{P\}} \cos \delta\right) \\
Y_{R}= & -\left(1+a_{H}\right)\left(F_{R Y\{S\}} \cos \delta-F_{R X\{S\}} \sin \delta+F_{R Y\{P\}} \cos \delta-F_{R X\{P\}} \sin \delta\right) \\
N_{R}= & -\left(x_{R}+a_{H} x_{H}\right)\left(F_{R Y\{S\}} \cos \delta-F_{R X\{S\}} \sin \delta+F_{R Y\{P\}} \cos \delta-F_{R X\{P\}} \sin \delta\right) \\
& +\left(1-t_{R\{P\}}\right) y_{R\{S\}}\left(F_{R\{S\}} \sin \delta+F_{R X\{S\}} \cos \delta-F_{R Y\{P\}} \sin \delta-F_{R X\{P\}} \cos \delta\right) \\
K_{R}= & -z_{R} Y_{R}
\end{array}\right\}
$$

The hull, propeller and rudder interaction coefficients $\left(x_{R}, a_{H}, x_{H}\right.$, etc. $)$ are taken from the existing mathematical model for the respective ships. The propeller model is shown in Eqs. $8 \sim 9$. We consider the hull propeller interaction coefficients $t_{P}, w_{P 0}, \eta_{R}$ constant for different wind/ wave conditions. Speed reduction is one of the solutions being proposed at IMO to reduce emissions in the immediate future. Reducing speed is suggested as an important means to reduce emissions from international commercial shipping [37,38]. Voluntary speed reduction has a human decision-making element. In this paper, only involuntary speed reduction due to constant main engine torque is considered for simulations. Therefore, the propeller revolution will vary as its thrust loading changes. For e.g. when the resistance of the ship in surge direction increases due to wind, wave and rudder motions, the propeller becomes overloaded. This results in a drop in propeller rpm and thereby the ship's speed. Therefore, the propeller thrust and torque are coupled with ship's speed in our maneuvering model.

$$
\left.\left.\begin{array}{l}
X_{P}=\left(1-t_{P}\right) \rho n^{2} D_{P}^{4} K_{T} \\
K_{T}=A_{1}+A_{2} J_{p}+A_{3} J_{P}^{2}
\end{array}\right\} \begin{array}{l}
2 \pi\left(J_{P P}+\Delta J_{P P}\right) \dot{n}+\rho n^{2} D_{P}^{5} K_{Q}=Q_{E} \\
K_{Q}=B_{1}+B_{2} J_{p}+B_{3} J_{P}^{2}
\end{array}\right\}
$$

The added moment of rotary inertia of propeller in water is taken as $25 \%$ of the propeller's moment of rotary inertia in the air [39]. The propeller torque model shown in Eq. 9, introduces an additional degree of freedom in the system, i.e. the propeller revolution variation. Besides the propeller and hull characteristics, the propeller revolution variation also depends on the characteristics of the prime mover. We consider the prime mover to be a diesel engine working in constant torque operating condition. For all the ship models, the prime mover is directly connected to the propeller through the shaft. There is no reduction gear. Therefore, the propeller and engine revolutions are the same. The constant engine 
Numerical simulation of ship navigation in rough seas based on ECMWF data
Patil Prasad Vinayak, Chelladurai Sree Krishna Prabu, Nagarajan Vishwanath, Sha Om Prakash

torque is fixed based on the design calm water speed of the respective vessels. When added resistance due to wave/ wind is considered, the engine torque remains the same while the propeller revolution and the ship speed varies as per the ship and propeller characteristics. The fuel consumption is computed as shown in Eq. 10. ' $\mathrm{T}$ ' is the total voyage time.

$$
T F C=\int_{0}^{T}\left(S F O C * 2 \pi n Q_{E} * d t\right)
$$

The SFOC is specified by the main engine manufacturer. In this paper, it is considered the same for all the three-ship models i.e. $170 \mathrm{~g} / \mathrm{kW}$.hr. Resistance due to the wind acting on the hull and superstructure depends on the direction and the speed of the wind and the ship's superstructure characteristics. This resistance is proportional to the square of the ship's speed and the cross-sectional area of the vessel above the waterline. The ship's resistance can be divided into different components like hull resistance, added wave resistance, wind resistance etc. Calm water resistance for the 3 ship models is shown in Fig. 13. Holtrop's formula is used for calculating the form factor of the hull.



Fig. 13 Calm water-resistance of DTMB 5415, PCC and VLCC ship types

During the voyage, the ship experiences added resistance due to two wave systems: the reflection of short waves on the hull, and the wave-induced heave and pitch motions of the vessel. The magnitude of added resistance depends on various parameters like the vessel dimension and wave factors like $\mathrm{H}_{1 / 3}, \mathrm{MWP}$, and wave direction. The wave spectrum is calculated for each significant wave height mean wave period. The wave spectrum for $\mathrm{H}_{1 / 3}=$ $5 \mathrm{~m}$ and, MWP $=11.88 \mathrm{sec}$ is shown in Fig. 14. This resistance component is created by the loss of energy to both, radiated waves caused by vessel motion, and diffraction of incident waves on vessel hull $[8,40]$. The RAO (Relative Amplitude Operator) of added wave resistance of the vessel is calculated using Maxsurf software [41]. The variation of RAO of added wave resistance for wave heading angles ranging from $180^{\circ}$ (head sea) to $90^{\circ}$ (beam sea) is shown in Fig. 15. The nature of the added wave resistance curve is similar to [41,42]. The RAO of added wave resistance from $90^{\circ}$ (beam sea) to $0^{\circ}$ (following sea) is very less and hence it is neglected in this study [43,44]. The Salvesen method is used for calculating RAO as it is more suitable for oblique waves and low-speed ships. Also, the Salvesen method is more accurate than the Gerritsma and Beukelman method for a wide range of hull shapes [41]. Bretschneider wave spectrum used for analysis is shown in Eq. 11. The wave encounter angle is calculated in the ship coordinate system from wave heading angle and ship heading angle as shown in Eq. 12. The wave encounter frequency and encounter spectrum are 
computed using Eqs. $12 \sim 13$ respectively. The added wave resistance is calculated from RAO and wave energy spectrum by multiplying and integrating the contribution of all the individual wave frequencies. The added resistance due to wave at a geographical location is computed by Eq. 14. The wave spectrum at a geographical location is determined based on the averaged values of the significant wave height and mean wave period obtained from the satellite data as described in the previous section.

$$
\begin{aligned}
& S(\omega)=\frac{5}{16} \frac{\omega_{m}^{4}}{\omega_{\text {wave }} 5} H_{1 / 3}^{2} e^{-5 \omega_{m}^{4} / 4 \omega_{\text {wave }}{ }^{4}} \\
& \left.\begin{array}{l}
\psi_{\text {wave }}=\psi_{\text {wave }}-\psi \\
\omega_{e}=\omega_{\text {wave }}-\frac{\omega_{\text {wave }} u * \cos \left(\psi_{\text {wave }}\right)}{g}
\end{array}\right\} \\
& S\left(\omega_{e}\right)=\frac{S(\omega)}{1-\left(2 \omega_{\text {wave }} u / g\right) * \cos \left(\psi_{\text {wave }}\right)} \\
& R_{A W}=2 \int_{0}^{\infty} S\left(\omega_{e}\right) \frac{R_{a w}}{\varsigma^{2}} d \omega_{e} \\
& X_{A W}=R_{A W} \cos \left(\psi_{\text {Wave }}\right) \\
& Y_{A W}=R_{A W} \sin \left(\psi_{\text {Wave }}\right) \\
& \int_{0}
\end{aligned}
$$

Fig. 14 Bretschneider wave spectrum for $=5 \mathrm{~m}$ and modal period $=11.88 \mathrm{sec}$ 
Numerical simulation of ship navigation in rough seas based on ECMWF data
Patil Prasad Vinayak, Chelladurai Sree Krishna Prabu, Nagarajan Vishwanath, Sha Om Prakash

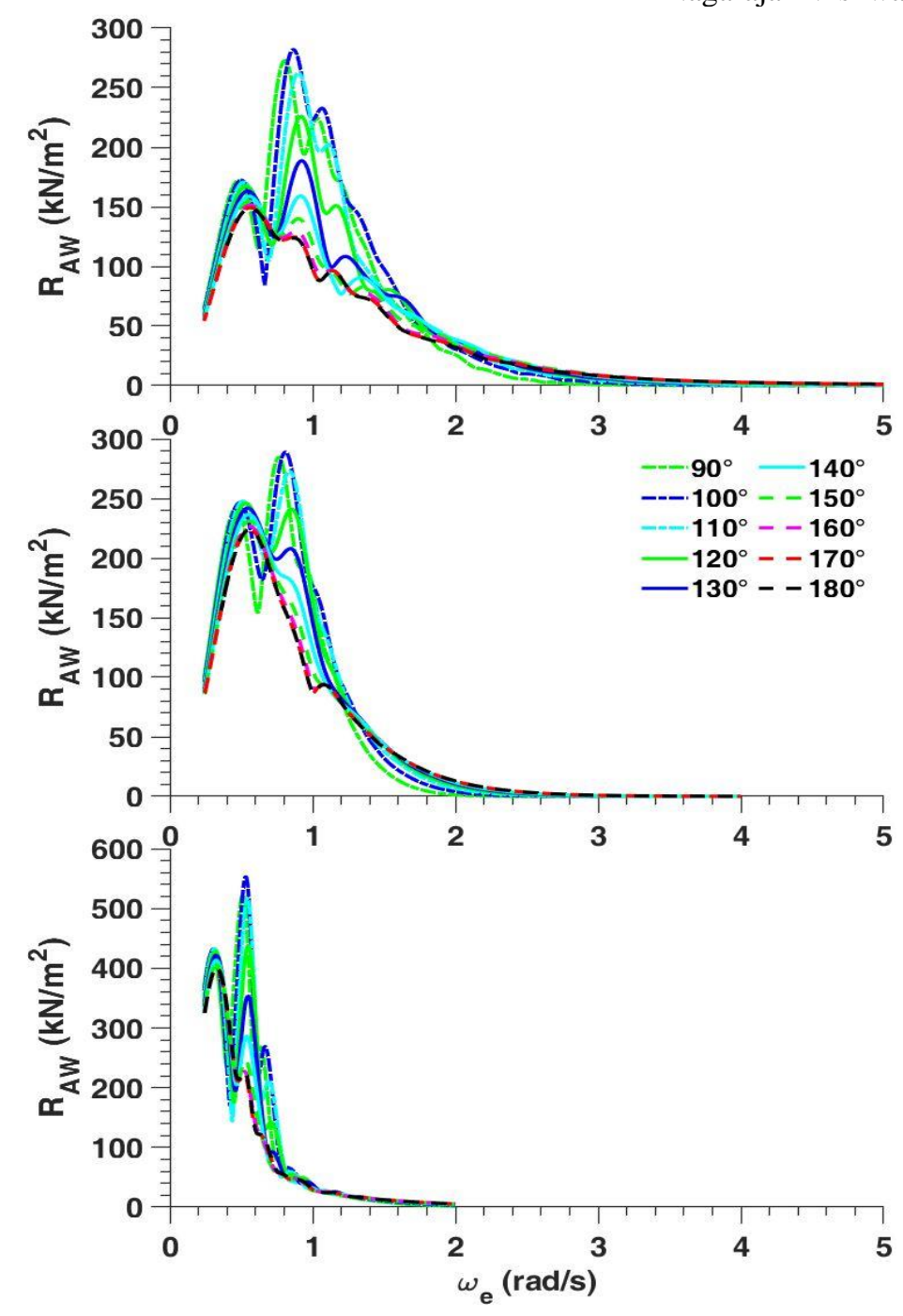

Fig. 15. Variation of added wave resistance for different wave direction. Top: DTMB, Middle: PCC and Bottom: VLCC ship at 10-knot speed

The expressions of the forces and the moment induced by wind are shown in Eqs. 15 18.

$$
\begin{aligned}
& X_{W}=\rho_{A} A_{T} U_{A}^{2} C_{X}\left(\psi_{A}\right) / 2 \\
& Y_{W}=\rho_{A} A_{L} U_{A}^{2} C_{Y}\left(\psi_{A}\right) / 2 \\
& N_{W}=\rho_{A} A_{L} U_{A}^{2} L_{O A} C_{N}\left(\psi_{A}\right) / 2 \\
& K_{W}=\rho_{A} A_{A}^{2} U_{A}^{2} C_{K}\left(\psi_{A}\right) / 2 L_{O A}
\end{aligned}
$$

The wind force coefficients $C_{X}\left(\psi_{A}\right), C_{Y}\left(\psi_{A}\right), C_{N}\left(\psi_{A}\right), C_{K}\left(\psi_{A}\right)$ are computed based on the above water area characteristics of the individual vessels. The regression formula by Fujiwara et al. [45] was used to estimate the aerodynamic drag coefficients. The wind speed and direction at $1^{\circ}$ latitude/ longitude interval is obtained from the weather characteristics described in the previous section. The effective wind speed and wind angle of attack in the ship fixed coordinate system is computed as shown in Eq. 19. 


$$
\left.\begin{array}{l}
\psi_{R}=\psi-\psi_{W} \\
U_{A}^{2}=\left(-u+U_{G W} \cos \psi_{R}\right)^{2}+\left(-v+U_{G W} \sin \psi_{R}\right)^{2} \\
\psi_{A}=\tan ^{-1}\left(\left(-v+U_{G W} \sin \psi_{R}\right) /\left(-u+U_{G W} \cos \psi_{R}\right)\right)
\end{array}\right\}
$$

The aerodynamic forces and moment induced by gust wind are considered in this study. Gust wind time series is generated using the Harris spectrum [46] as shown in Eq. 20. Harris spectrum is used because it has the wind speed variance as one of the model parameters besides the mean wind speed. Higher variance for the same mean wind speed will mean higher peaks in the gust wind time series. Mean wind speed and wind speed variance from satellite data are used for simulations. The gust wind velocity is obtained by Eq. 21. The amplitude of the $\mathrm{i}^{\text {th }}$ wind component is determined under a linear theory as shown in Eq. 22 .

$$
\begin{aligned}
& S_{z}=\sigma_{U}^{2} \frac{4 \frac{L_{U}}{U_{W}}}{\left(1+70.8\left(\frac{L_{U}}{U_{W}}\right)^{2}\right)^{5 / 6}} \\
& \left.\begin{array}{l}
U(t)=\sum_{i=1}^{N} b_{i} \sin \left(\omega_{i} t+\delta_{i}\right) \\
U_{G W}=U_{W}+U(t)
\end{array}\right\} \\
& b_{i}=\sqrt{2 S_{z}\left(\omega_{i}\right) \Delta \omega_{i}}
\end{aligned}
$$

Here, $\Delta \omega_{i}$ is the discretized interval of the $i$ th wind component. To avoid repeating patterns of gust wind, non-evenly distributed discrete frequencies were used. A small interval $\Delta \omega_{i}$ is taken for higher accuracy of integration. The phase angle $\delta_{i}$ is generated as a random number during simulations. For a particular zone $\left(1^{\circ}\right.$ latitude $\mathrm{x} 1^{\circ}$ longitude) where wind speed and its variance is assumed as constant, the same seed is used for random number generation. The wind speed used for simulation is in the range $0 \sim 15 \mathrm{~m} / \mathrm{s}$ and the effective frequency range for this wind speed is observed to be $\omega=0 \sim 10 \mathrm{radians} / \mathrm{s}$.

The voyage simulations are carried out for long distances on the surface of the Earth. The Earth is considered to be an ellipsoid surface for this purpose. To get the voyage length and time, we need to transform the ship dynamics (from MMG model) from the Cartesian coordinate system to the ECEF coordinate system. Additionally, the weather information (wind and wave characteristics) is received with respect to the ECEF coordinate system. A set of auxiliary equations are required to carry out this transformation. First, the ship dynamics are transformed into NED (North East Down) coordinate system. This is shown in Eqs. $23 \sim 24$. In these equations, $\mathrm{s}(\bullet)=\sin (\bullet), \mathrm{c}(\bullet)=\cos (\bullet), \mathrm{t}(\bullet)=\tan (\bullet)$ and $\theta=\mathrm{q}=0$ for 4 degree of freedom model. The ship dynamics in the NED frame are transformed to latitude, longitude and depth system [47] as shown in Eq. 25. The different parameters in Eq. 25 are calculated as shown in Eq. 26.

$$
\left\{\begin{array}{l}
\dot{X}_{E} \\
\dot{Y}_{E} \\
\dot{Z}_{E}
\end{array}\right\}=\left[\begin{array}{ccc}
c \psi & -\mathrm{s} \psi & 0 \\
s \psi & \mathrm{c} \psi & 0 \\
0 & 0 & 1
\end{array}\right]\left[\begin{array}{ccc}
c \theta & 0 & \mathrm{~s} \theta \\
0 & 1 & 0 \\
-\mathrm{s} \theta & 0 & \mathrm{c} \theta
\end{array}\right]\left[\begin{array}{ccc}
1 & 0 & 0 \\
0 & c \phi & -\mathrm{s} \phi \\
0 & s \phi & \mathrm{c} \phi
\end{array}\right]\left\{\begin{array}{l}
u \\
v \\
w
\end{array}\right\}
$$


Numerical simulation of ship navigation in rough seas based on ECMWF data

$$
\begin{aligned}
& {\left[\begin{array}{c}
\dot{\phi} \\
\dot{\theta} \\
\dot{\psi}
\end{array}\right]=\left[\begin{array}{ccc}
1 & s(\phi) t(\theta) & c(\phi) t(\theta) \\
0 & c(\phi) & -s(\phi) \\
0 & s(\phi) / c(\theta) & c(\phi) / c(\theta)
\end{array}\right]\left[\begin{array}{l}
p \\
q \\
r
\end{array}\right]} \\
& \dot{\varphi}_{b}=\frac{\dot{X}_{E}}{R_{N}\left(\varphi_{b}\right)+h_{b}} \\
& \left.\dot{\lambda}_{b}=\frac{\dot{Y}_{E}}{\left(R_{N}\left(\varphi_{b}\right)+h_{b}\right) * \cos \left(\varphi_{b}\right)}\right\} \\
& \dot{h}_{b}=-\dot{Z}_{E} \\
& h_{b}=\frac{\sqrt{\left(\left(x_{e b}^{e}\right)^{2}+\left(y_{e b}^{e}\right)^{2}\right)}}{\cos \left(\varphi_{b}\right)}-R_{E Q}\left(\varphi_{b}\right) \\
& R_{E}\left(\varphi_{b}\right)=\frac{R_{P L}}{\sqrt{\left(1-e^{2} * \sin ^{2} \varphi_{b}\right)}} \\
& R_{N}\left(\varphi_{b}\right)=\frac{R_{P L}\left(1-e^{2}\right)}{\left(1-e^{2} * \sin ^{2} \varphi_{b}\right)^{3 / 2}}
\end{aligned}
$$

At the beginning of the voyage simulation, the latitude, longitude, depth, Euler angles, ECEF coordinates, etc. are input in the model. This is based on the port from where the vessel commences its voyage. Thereafter, the time series of these parameters is generated by integrating the motion equations. The desired voyage trajectory is generated beforehand based on the great ellipse navigation system. Waypoint coordinates are generated at about $1^{\circ}$ latitude/ longitude interval [48]. It may be noted that a ship has to travel a longer distance for covering $1^{\circ}$ longitude in Equator area as compared to the Polar area. Due to wind, surge/ sway forces and yaw moment act on the vessel. Due to wave, surge and sway force act on the ship. Due to this reason, the vessel tends to drift off its desired course. An autopilot is required which will automatically generate suitable rudder angle command to keep the ship in its desired trajectory. The ship is guided through the waypoints by using a course-keeping PD autopilot as shown in Eq. 27. The gain settings C1, C2 used for different ship types are shown in Table 1. The gain settings $\mathrm{C} 1$ and $\mathrm{C} 2$ are calculated by the trial and error method. This means the gain coefficients are varied and the ship response to the rudder command is checked manually. The gain coefficient where the ship response is satisfactory is selected. The desired waypoints are given as input. The waypoints are given in the sequence in which we want the ship to navigate. The bearing angle between the initial position of the ship (point 1) and first waypoint (point 2) is calculated using Eq. 28. This bearing angle becomes the desired heading angle $\left(\psi_{D}\right)$. As the ship navigates, points 1 and 2 get automatically updated. During navigation, the ship may or may not drift from its course. Desired heading angle $\left(\psi_{D}\right)$ in Eq. 27 is updated at each time instant using Eq. 28 during ship navigation [49]. This generates the commanded rudder angle as per autopilot shown in Eq. 28. Maximum rudder angle $\left( \pm 35^{\circ}\right)$, minimum rudder angle $\left( \pm 0.01^{\circ}\right)$ and maximum rudder rate $( \pm 2.5 \%$ sec for PCC and VLCC and, $\pm 9 \%$ sec for DTMB 5415) limiters are applied after the commanded rudder angle is generated. As soon as the ship reaches within the radius of twice the length of a ship of point 2 , point 2 is updated with the next waypoint from the input table [50]. At each time instant, the geodetic distance between the present position of the ship and point 2 is 
calculated using Vincenty's formula [49] shown in Eq. 29. The details of Eq. 29 are given in Appendix B. The term "ds" is a function of latitude and longitude. Equation 29 is solved iteratively. The iteration is stopped when the distance is computed within $1 \mathrm{~m}$ accuracy. This way the numerical simulation and ship's automatic navigation proceeds. It is observed that for the waypoint navigation simulation, it is necessary to compute the instantaneous latitude/ longitude position of the ship. This entails extra computation effort.

$$
\begin{aligned}
& \delta_{\text {Control }}=C_{1}\left(\psi_{D}-\psi\right)-C_{2} r^{\prime} \\
& \psi_{D}=a \tan 2(y, x) \\
& d s=R_{P L} * A A^{*}\left(\sigma_{a}-\Delta \sigma_{a}\right)
\end{aligned}
$$

Where,

$$
\begin{gathered}
y=\cos U_{1} * \sin \Delta \lambda \\
x=\cos U_{1}^{*} \sin U_{2}-\sin U_{1} * \cos U_{2} * \cos \Delta \lambda \\
\tan \left(U_{1}\right)=(1-f) * \tan \varphi_{1}, \tan \left(U_{2}\right)=(1-f) * \tan \varphi_{2}, f=\left(R_{E Q}-R_{P L}\right) / R_{E Q}
\end{gathered}
$$

The track length travelled by ship at each time step during simulation is computed using Eq. 30. The discrete track lengths obtained by Eq. 30 when added together gives the total track length traversed by the ship between the origin and destination points. This track length will be usually longer than the great ellipse trajectory length, between the origin and destination point, which is computed by Eq. 29. This is because, during the actual voyage, the vessel keeps drifting off its desired trajectory due to wind and wave. The autopilot tends to bring back the ship to the desired trajectory/ course. The resistance increment is not only due to wind/ wave force but also due to rudder/ ship motions. The time and fuel consumption for the entire voyage is known from the simulation output. It may be noted that this procedure is different from optimal ocean routing. In ocean routing, an optimal trajectory path is generated based on a predefined criterion, minimizing time of travel or fuel consumption or constant engine torque condition, etc. Several sets of trajectories are generated and the optimal amongst them is selected. A suitable algorithm and an additional set of simulations need to be carried out for this purpose.

$$
d s=\sqrt{(d x)^{2}+(d y)^{2}}
$$

\section{Ship Simulation and Validation}

Engine torque used for the simulations is validated with the actual ship's data [51]. The typical main engine power and RPM of tankers and PCC ships is shown in Fig. 16. This figure illustrates, that tankers (of length $320 \mathrm{~m}$ approximately) have engine power in the range of $24000 \sim 32000 \mathrm{~kW}$ at $66 \sim 78 \mathrm{rpm}$. Similarly, PCC ship (of length $190 \mathrm{~m}$ approximately) have engine power in the range of $13000 \sim 16000 \mathrm{~kW}$ at $100 \sim 130 \mathrm{rpm}$. The engine power and rpm selected for PCC and VLCC ship in this study is indicated in the figure in blue and red colour circle respectively. 
Numerical simulation of ship navigation in rough seas based on ECMWF data
Patil Prasad Vinayak, Chelladurai Sree Krishna Prabu, Nagarajan Vishwanath, Sha Om Prakash

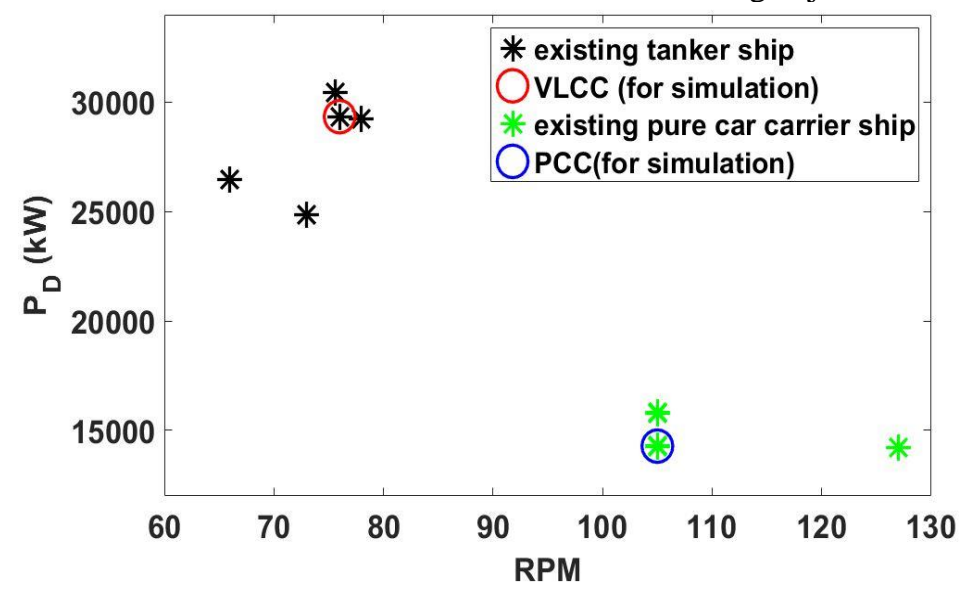

Fig. 16 Variation of main engine power with rpm of existing VLCC and PCC ships [51]

For validation of the maneuvering mathematical model, autopilot, zigzag and turning circle simulations at design speed are carried out. The output is shown in Figs. $17 \sim 19$ for DTMB 5415, PCC and VLCC ships respectively. Importantly, the engine rpm variation could be captured. It is observed that the maneuvering motion trajectories are similar to those of respective ship types $[6,36,52]$. It may be noted that model maneuvering tests are usually carried out with constant propeller revolution. The Mercator map for different oceanic voyages is shown in Fig. 20. The trajectory is discretized into waypoints and the distance between the successive waypoints is calculated using Vincenty's formula [49].
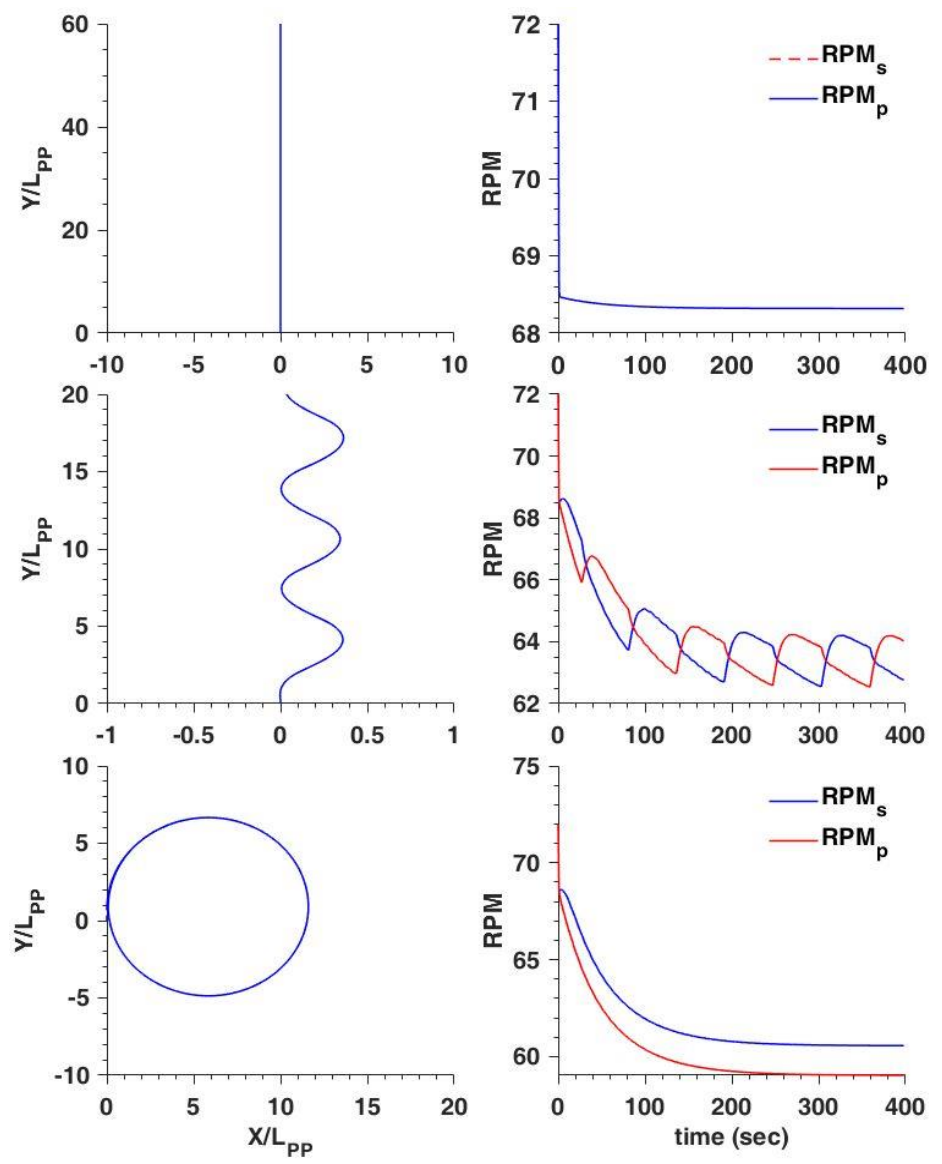

Fig. 17 DTMB 5415 ship manoeuvring. Top: autopilot navigation, Middle: $+10^{\circ}$ Zigzag manoeuvre, Bottom: $+35^{\circ}$ Turning circle manoeuvres. 
Patil Prasad Vinayak,

Chelladurai Sree Krishna Prabu,

Nagarajan Vishwanath, Sha Om Prakash
Numerical simulation of ship navigation in rough seas based on ECMWF data
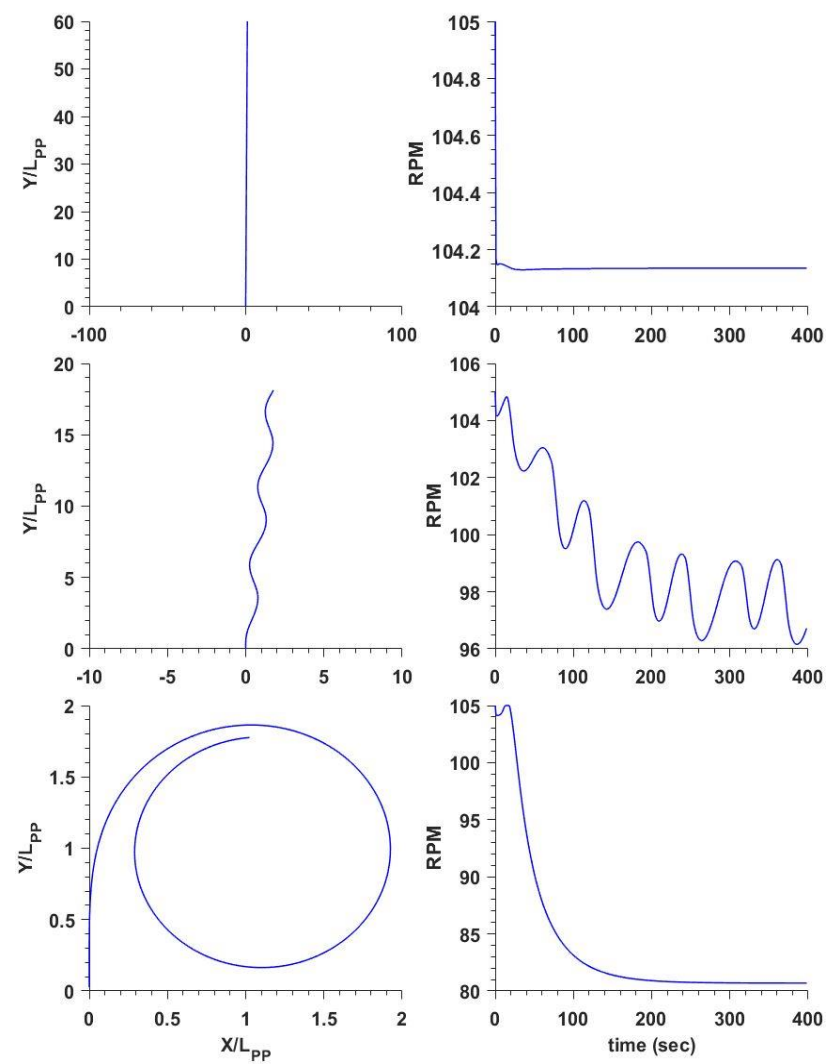

Fig. 18 PCC ship manoeuvring. Top: autopilot navigation, Middle: $+10^{\circ}$ Zigzag manoeuvre, Bottom: $+35^{\circ}$ Turning circle manoeuvre.
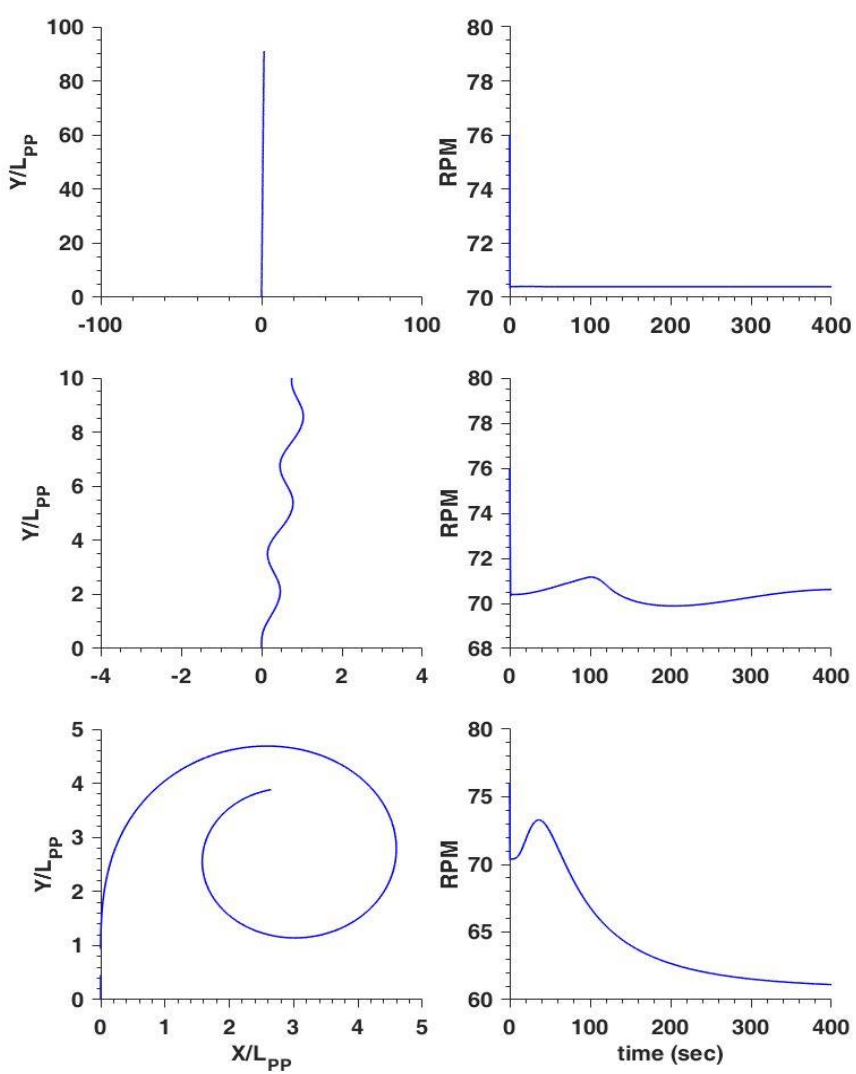

Fig. 19 VLCC ship manoeuvring. Top: autopilot navigation, Middle: $+10^{\circ}$ Zigzag manoeuvre, Bottom: $+35^{\circ}$ Turning circle manoeuvre. 

Nagarajan Vishwanath, Sha Om Prakash

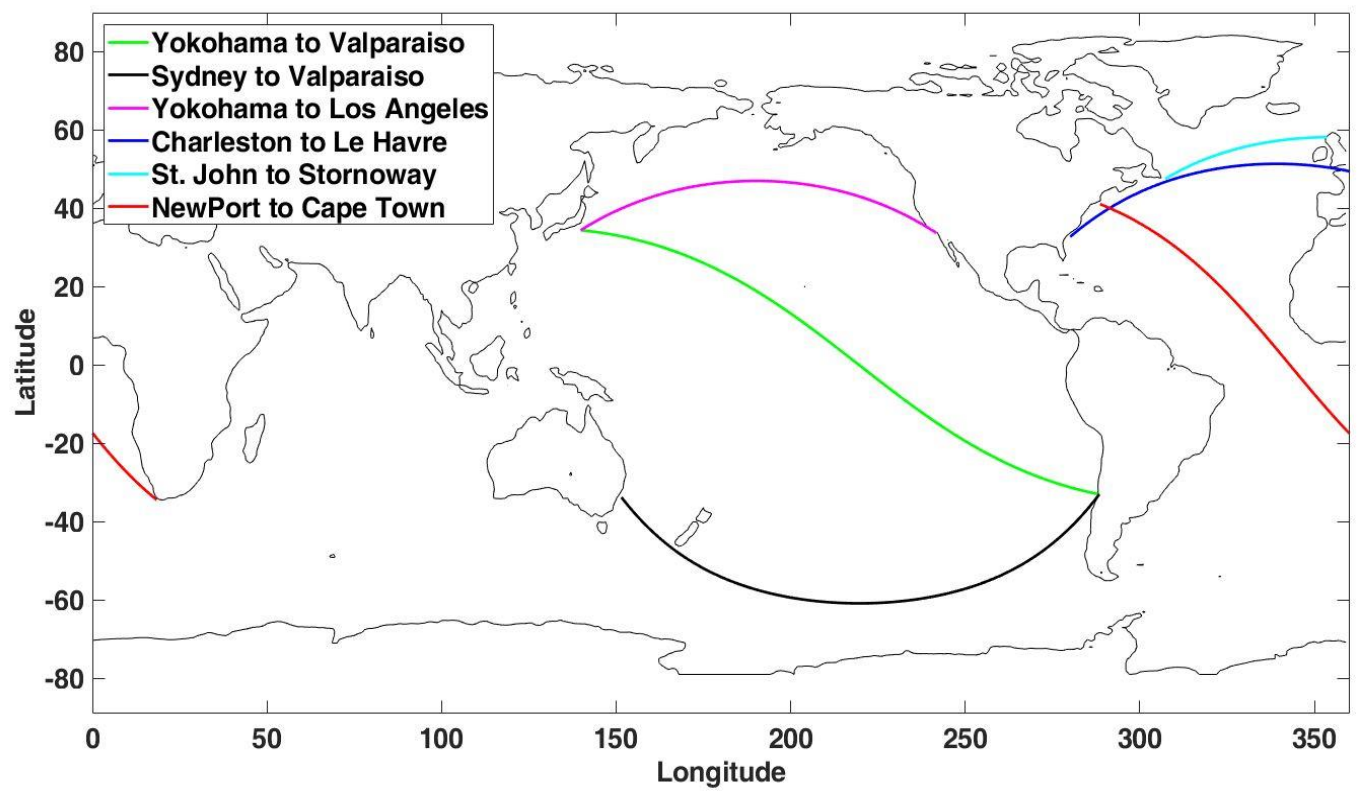

Fig. 20 The trajectory of some GES voyage on Mercator Chart

The engine power of VLCC is $26400 \mathrm{~kW}$ at $76 \mathrm{rpm}$, which is within the range of power and rpm of the VLCC tankers operating commercially. Similarly, the engine power of PCC is $13600 \mathrm{~kW}$ at $105 \mathrm{rpm}$, which is within the range of power and rpm of the PCC ships operating commercially. The power of a single-engine of DTMB 5415 is $2450 \mathrm{~kW}$ at $72 \mathrm{rpm}$. As per the change in resistance, the speed of ship changes and hence it implies a change in rpm as shown in Fig. 21. The engine power and RPM variation for the entire Sydney Valparaiso voyage of DTMB 5415, PCC and VLCC ship is shown in Fig. 21. This figure indicates the power and rpm range during the voyage is predicted accurately by our simulation model. Due to wind and wave effect, rpm changes continuously. Engine rpm changes due to change in wave height and wind speed. It results in a change in ship speed. In the southern ocean, North Atlantic Ocean and North Pacific Ocean, wave height and wind speed are higher. Hence, it results in larger reduction in ship speed in this ocean.

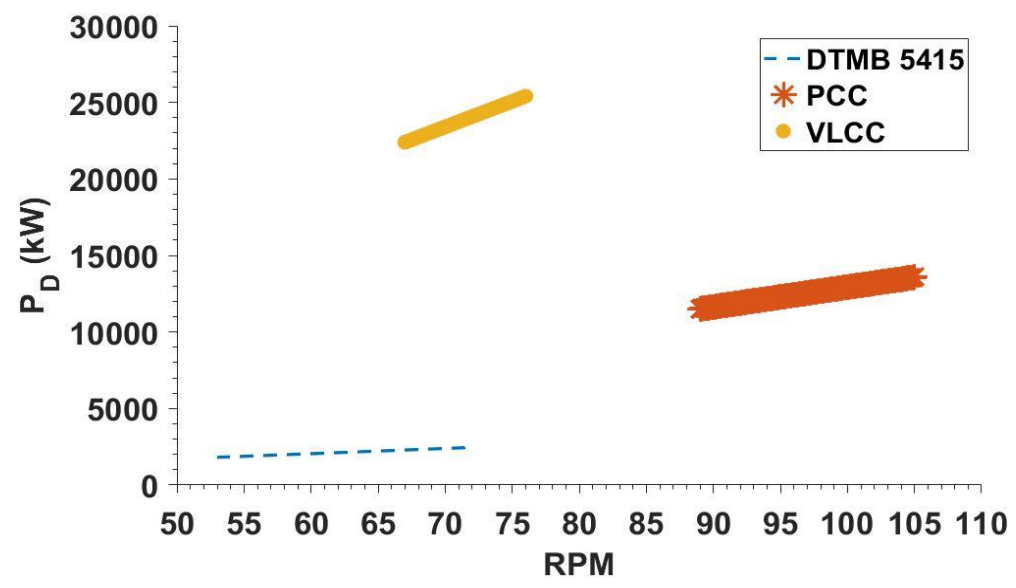

Fig. 21 Engine power/ RPM variation for the entire voyage

Six different voyages are selected for the simulation. The voyages are (1) Sydney (Australia) - Valparaiso (Chile), (2) Yokohama (Japan) - Valparaiso (Chile), (3) Newport (USA) - Cape Town (South Africa), (4) Yokohama (Japan) - Los Angeles (USA), (5) Charleston (USA) - Le Havre (France), (6) St. John Port (Canada) - Stornoway (UK). Figures $22 \sim 27$ show the simulation results of the DTMB 5415, PCC, and VLCC ships respectively. 
The to and fro voyage of above mentioned six routes are shown in contrasting colours for easy identification. Fuel consumption and voyage time in calm water condition are the same for to and fro voyages. Hence, the first histogram bar shows the same values. "92-01", "0918" and "92-18" represent results of 1992 - 2001, 2009 - 2018 and 1992 - 2018 respectively. The letters ' $S$ ' and ' $W$ " represent "summer zone" and "winter zone" respectively. Figures 22 $\sim 24$ shows that the fuel consumption of ships depends upon the Loadline zone (Season). The results show that both the fuel consumption and travel time is higher in winter zone as compared to the summer zone. This is due to higher wave height/ wave period and wind speed in winter as compared to summer zone. The fuel consumption in summer and winter varies in voyage $1,4,5$ and 6 . This is because wave and wind pattern varies with summer and winter season in this region. Fuel consumption in summer and winter in voyage 2 and 3 is nearly the same. This is because voyage 2 and 3 are in the tropical zone, where wave and wind pattern remains the same throughout the year. The difference in fuel efficiency between "summer" and "winter" voyages is more significant in the Southern Ocean, North Atlantic and North Pacific Oceans. Voyage number 1, 2, 3, 5 and 6 show the increase in fuel consumption in the recent 10 years. Only voyage 4 shows there is a decrease in fuel consumption in the recent 10 years. The difference has become more prominent in the recent decade as compared to previous years. Significantly, for all the 6 voyages, the fuel consumption is different for "to" and "fro" routes. This highlights the importance of wind and wave direction and shows that these must be considered for optimal ship routing. This will have a significant impact on the issue of environmental pollution reduction.

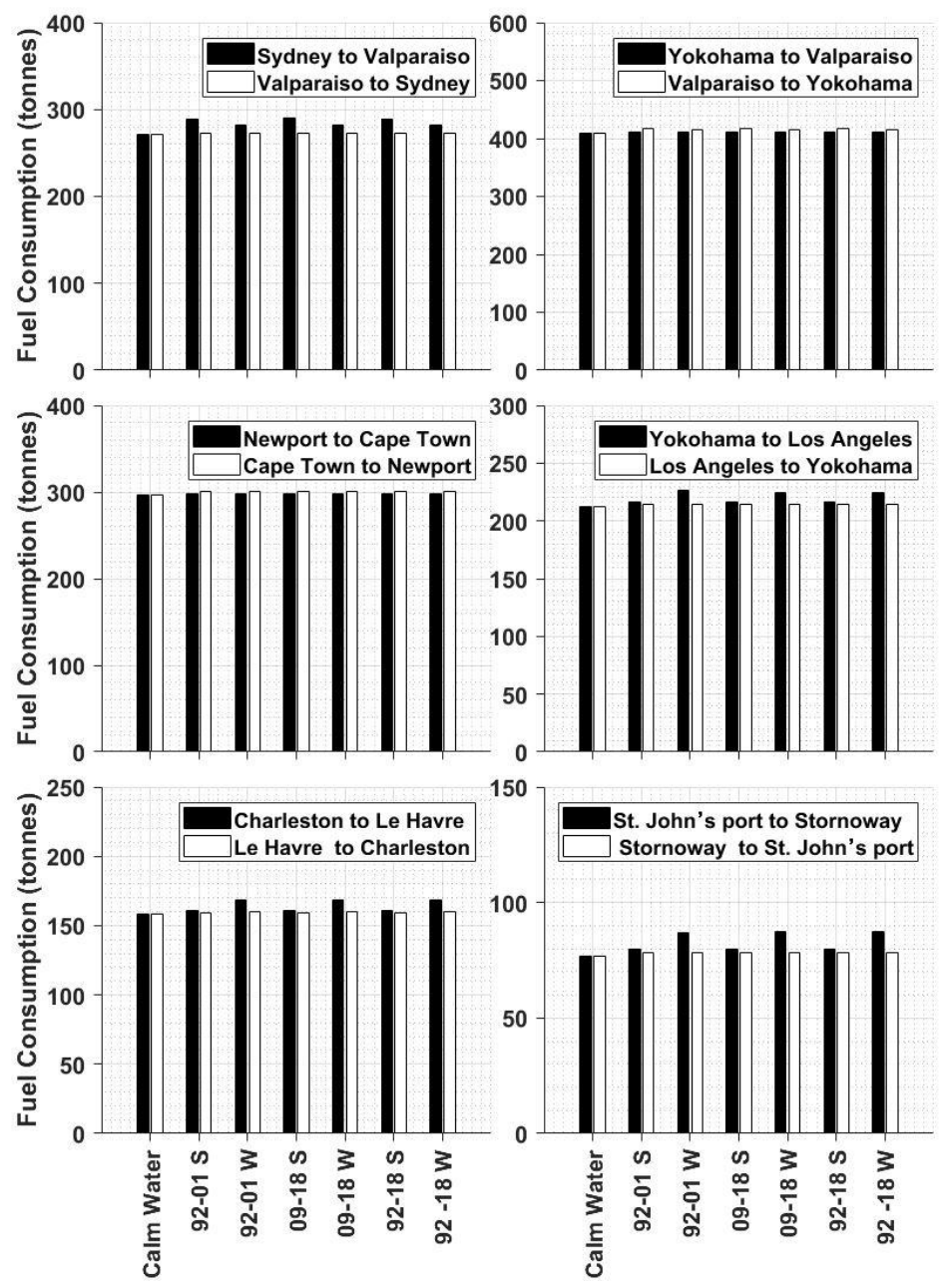

Fig. 22 DTMB 5415: Fuel Consumption (in tonnes) 
Numerical simulation of ship navigation in rough seas based on ECMWF data
Patil Prasad Vinayak,

Chelladurai Sree Krishna Prabu, Nagarajan Vishwanath, Sha Om Prakash

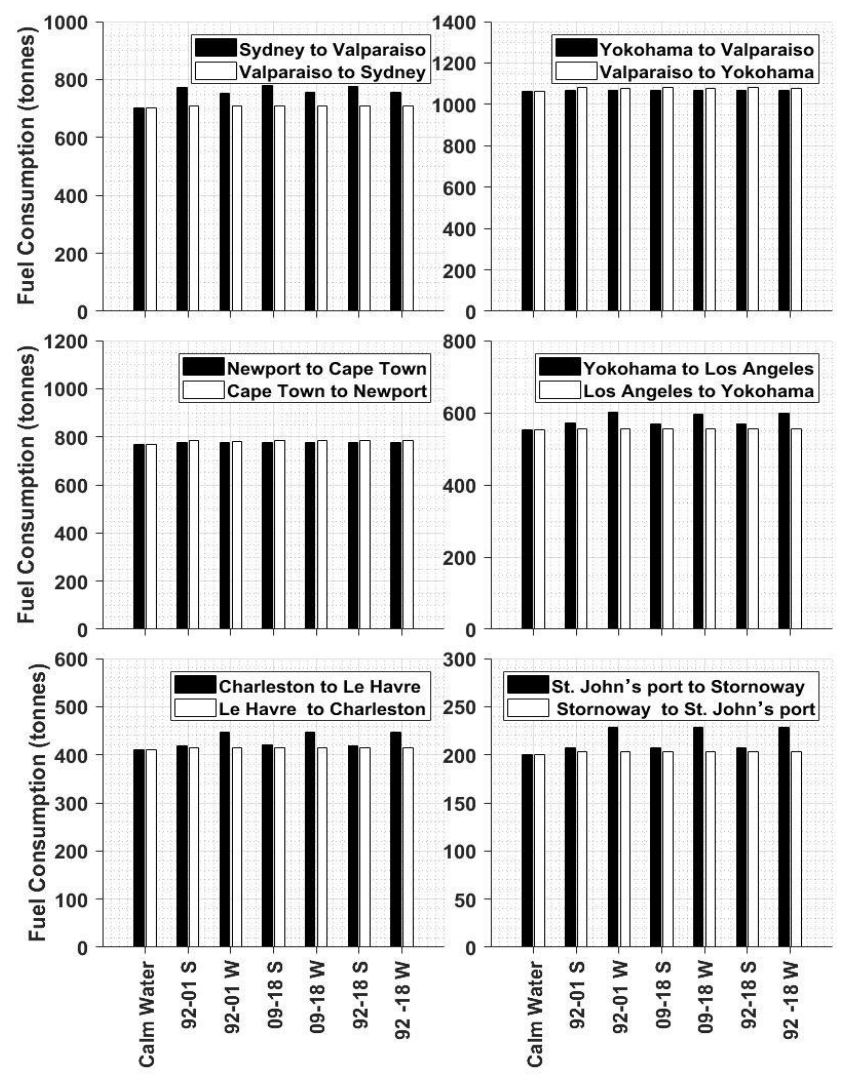

Fig. 23 PCC: Fuel Consumption (in tonnes)

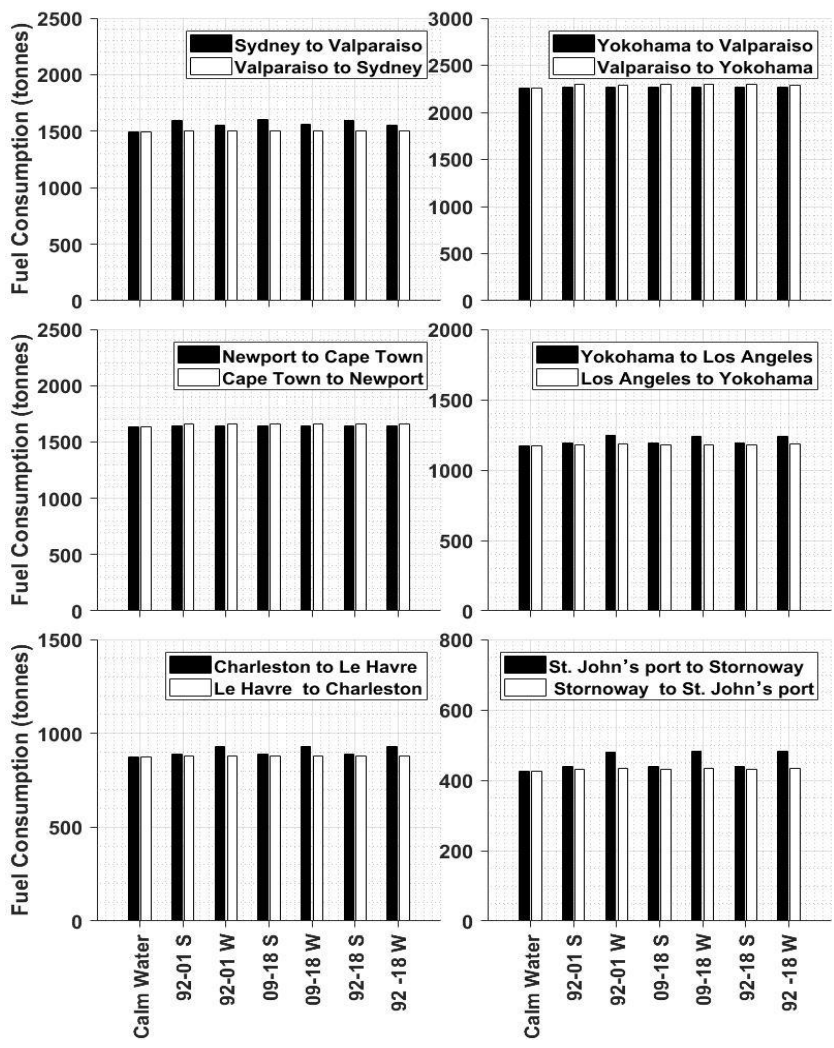

Fig. 24 VLCC: Fuel Consumption (in tonnes) 
Figures $25 \sim 27$ show the time of travel (in days) of a ship sailing from one port to another. It was shown in Fig. 3, that wave heights vary significantly between summer and winter seasons in the Southern Ocean and North Atlantic Ocean region. Therefore, the time required to complete the voyages is different in summer and winter seasons. Additionally, increased wave height and wind speed have been observed in the recent few years in these regions. Typically, wave heights are more in the Southern Ocean and North Atlantic zone as compared to other ocean areas. Wave height and wind speed change marginally in a tropical zone as shown in Figs $3 \sim 10$. Hence, tropical zones are suitable for voyages in all seasons. St. John's port to Stornoway (i.e. Voyage 6) is the shortest voyage as per distance. However, the difference in voyage time for summer and winter seasons is significant for this route. During this short voyage, a ship has to pass through the North Atlantic zone where the sea is usually rough during winter. Voyages $1,2,3,5$ and 6 show the increase in voyage duration in the recent 10 years. Only voyage 4 (Yokohama- Los Angeles) shows that there is a decrease in voyage duration in the recent 10 years. DTMB 5415 takes nearly 2.5 days more for a voyage from Sydney to Valparaiso than a voyage from Valparaiso to Sydney. This is mainly because of wave and wind direction. During Sydney to Valparaiso voyage, the ship mainly encounters head waves. While during Valparaiso to Sydney voyage, the ship mainly encounters the following waves. This implies that wave and wind direction is also important while ship routing.
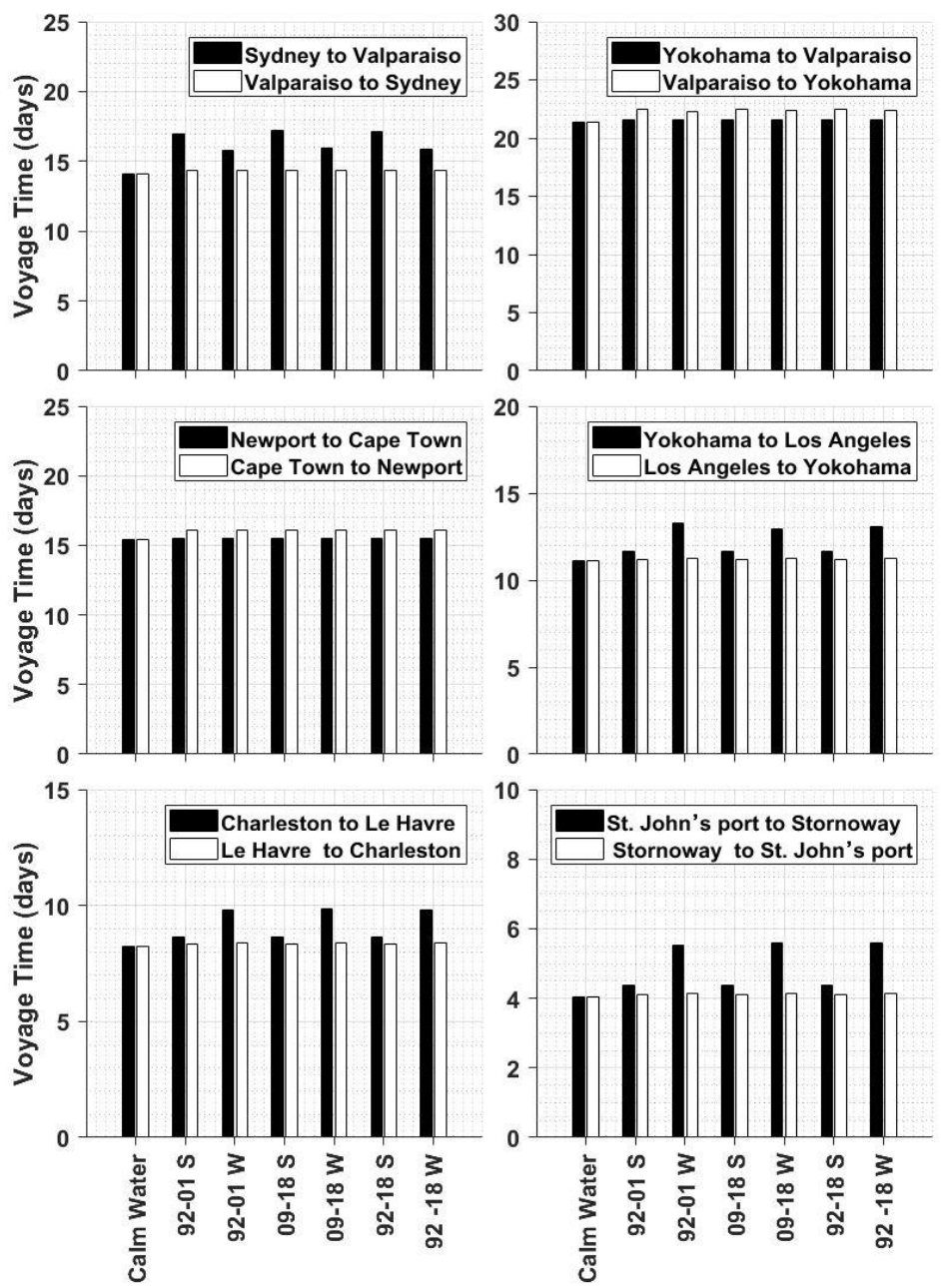

Fig. 25 Variation of voyage time for different navigation routes for DTMB 5415 ship (in days) 
Numerical simulation of ship navigation in rough seas based on ECMWF data
Patil Prasad Vinayak,

Chelladurai Sree Krishna Prabu, Nagarajan Vishwanath, Sha Om Prakash
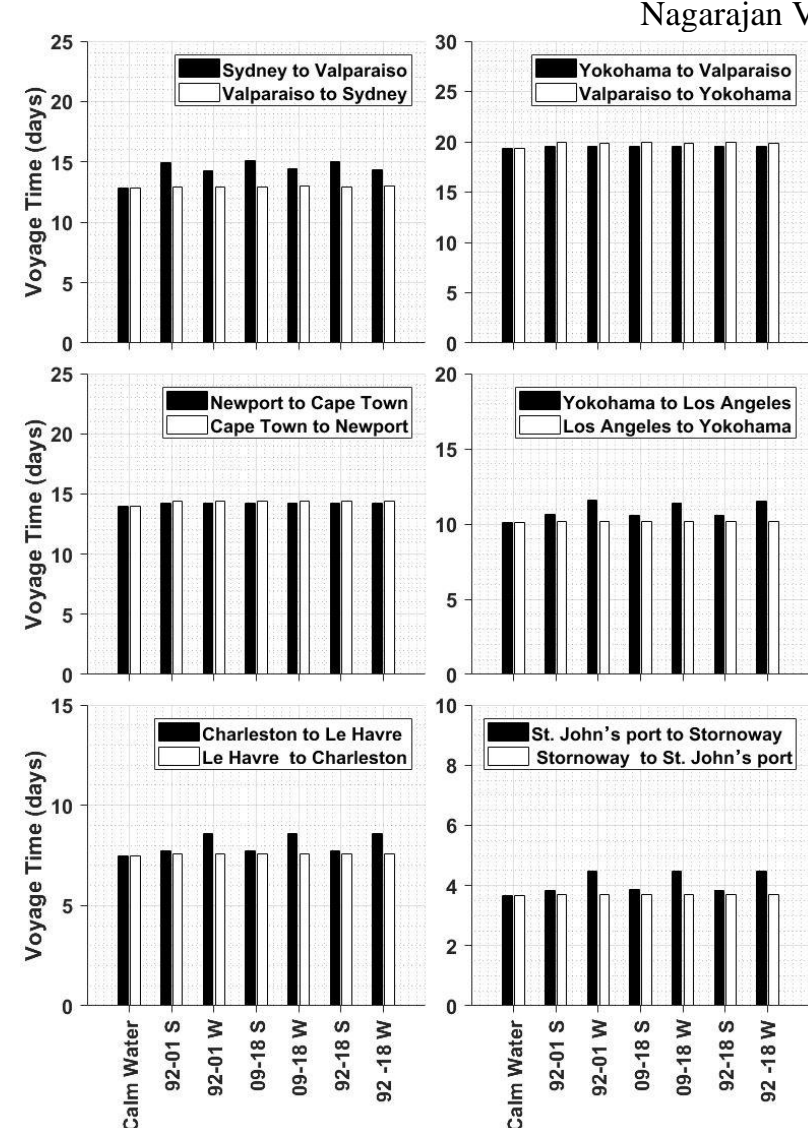

Fig. 26 Variation of voyage time for different navigation routes for PCC ship (in days)

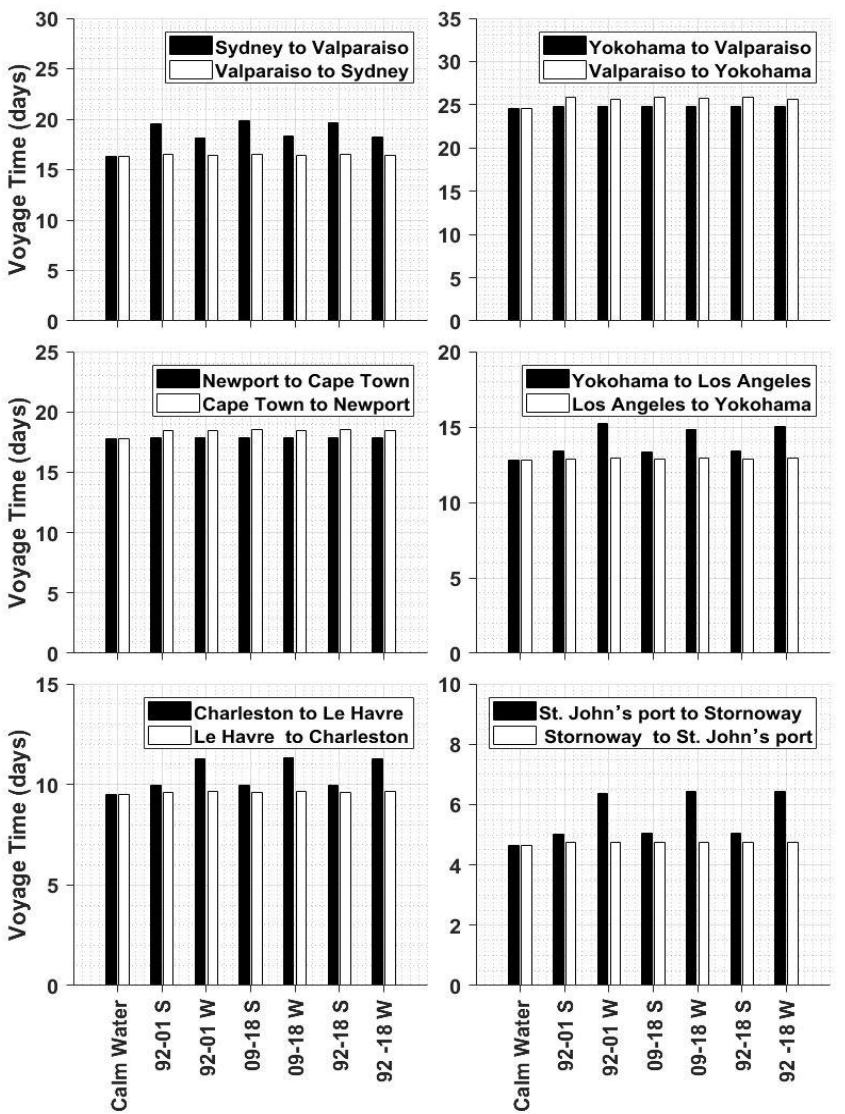

Fig. 27 Variation of voyage time for different navigation routes for VLCC ship (in days) 
Figures $28 \sim 30$ show the average ship speed during different voyages. The design speed for DTMB 5415, PCC and VLCC ship is 18, 20 and 15.7 knots respectively. For calm water condition, the average speed of the ship is the same as the design speed of the ship. However, for actual wave condition voyages, ship speed will decease than design speed. When the average ship speed is less, it implies that voyage time will increase. For Sydney to Valparaiso voyage, the average ship speed is nearly 3 knots less than the design speed due to more wave height in summer. Similarly, in winter, the average speed for Yokohama to St. John's Port voyage is nearly 4 knots less than the design speed. This shows how the study of wave and wind characteristics is necessary for a voyage. The ship speed will change drastically in summer and winter due to a change in wave height and wind speed. However, in the tropical zone (Voyage 2 and 3), the change in average ship speed during summer and winter is very small as compared to other voyages because of mild weather. The difference between average ship speed in first 10 years (1992-2001), last 10 years (2009-2018) and 27 years (1992-2018) is not significant. This is because the mean of weather data is taken for the simulation. The difference in mean values for first 10 years (1992-2001), last 10 years (20092018) and 27 years (1992-2018) is not so significant as to cause change in propulsive performance.

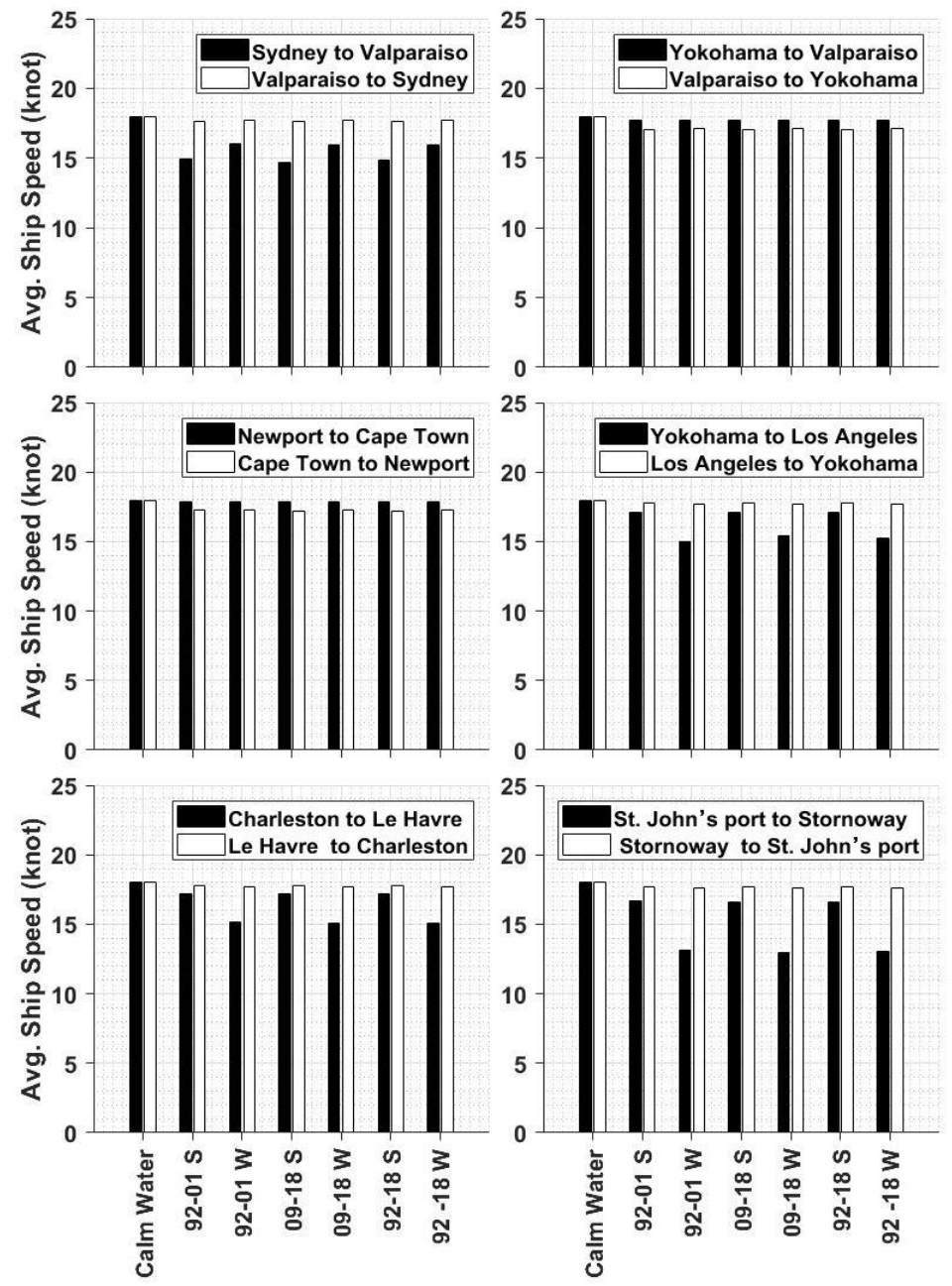

Fig. 28 Average ship speed for DTMB 5415 for different navigation routes (in knots) 
Numerical simulation of ship navigation in rough seas based on ECMWF data
Patil Prasad Vinayak,

Chelladurai Sree Krishna Prabu, Nagarajan Vishwanath, Sha Om Prakash

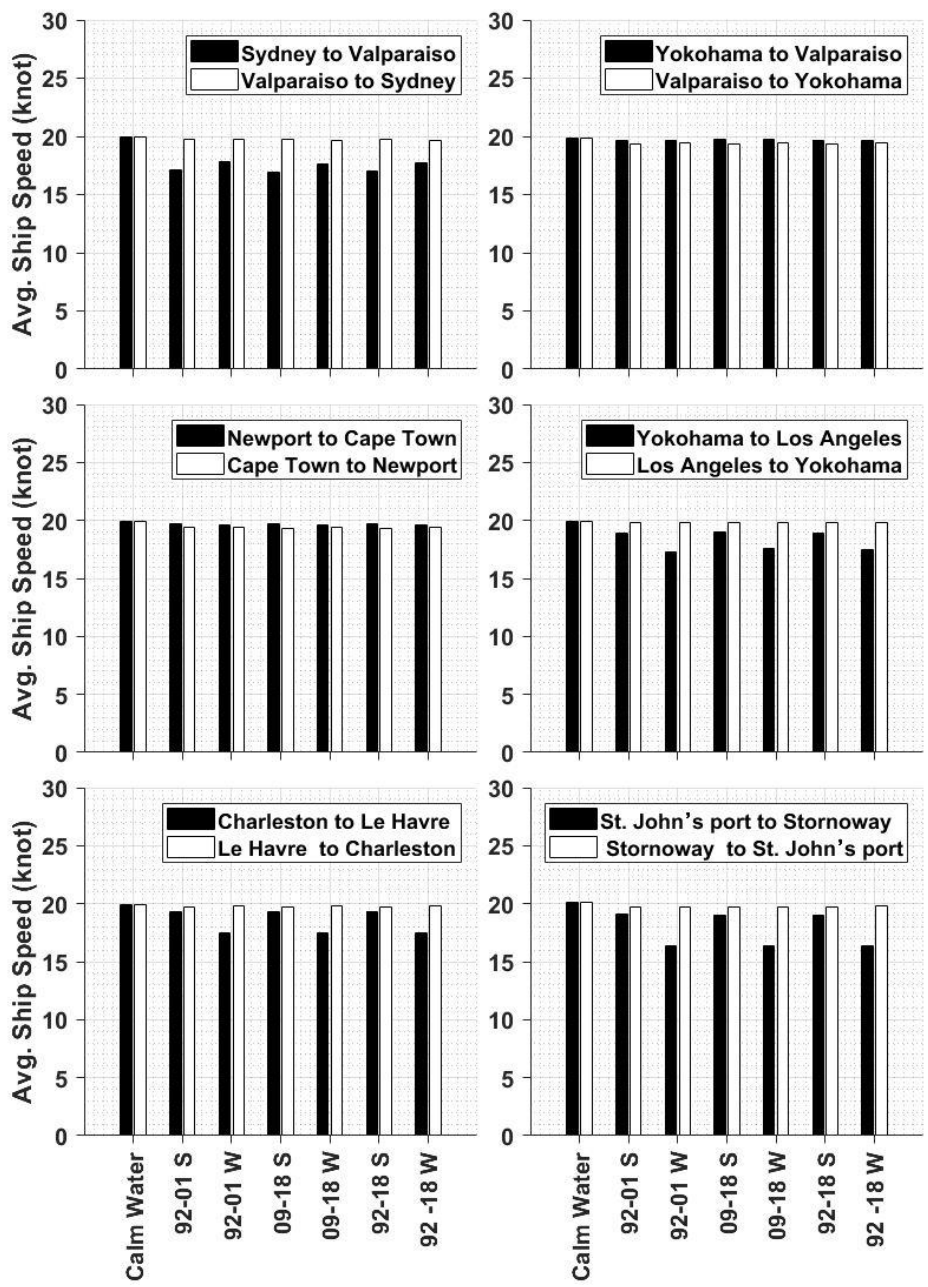

Fig. 29 Average ship speed for PCC ship for different navigation routes (in knots) 
Patil Prasad Vinayak,

Chelladurai Sree Krishna Prabu,

Nagarajan Vishwanath, Sha Om Prakash
Numerical simulation of ship navigation in rough seas based on ECMWF data
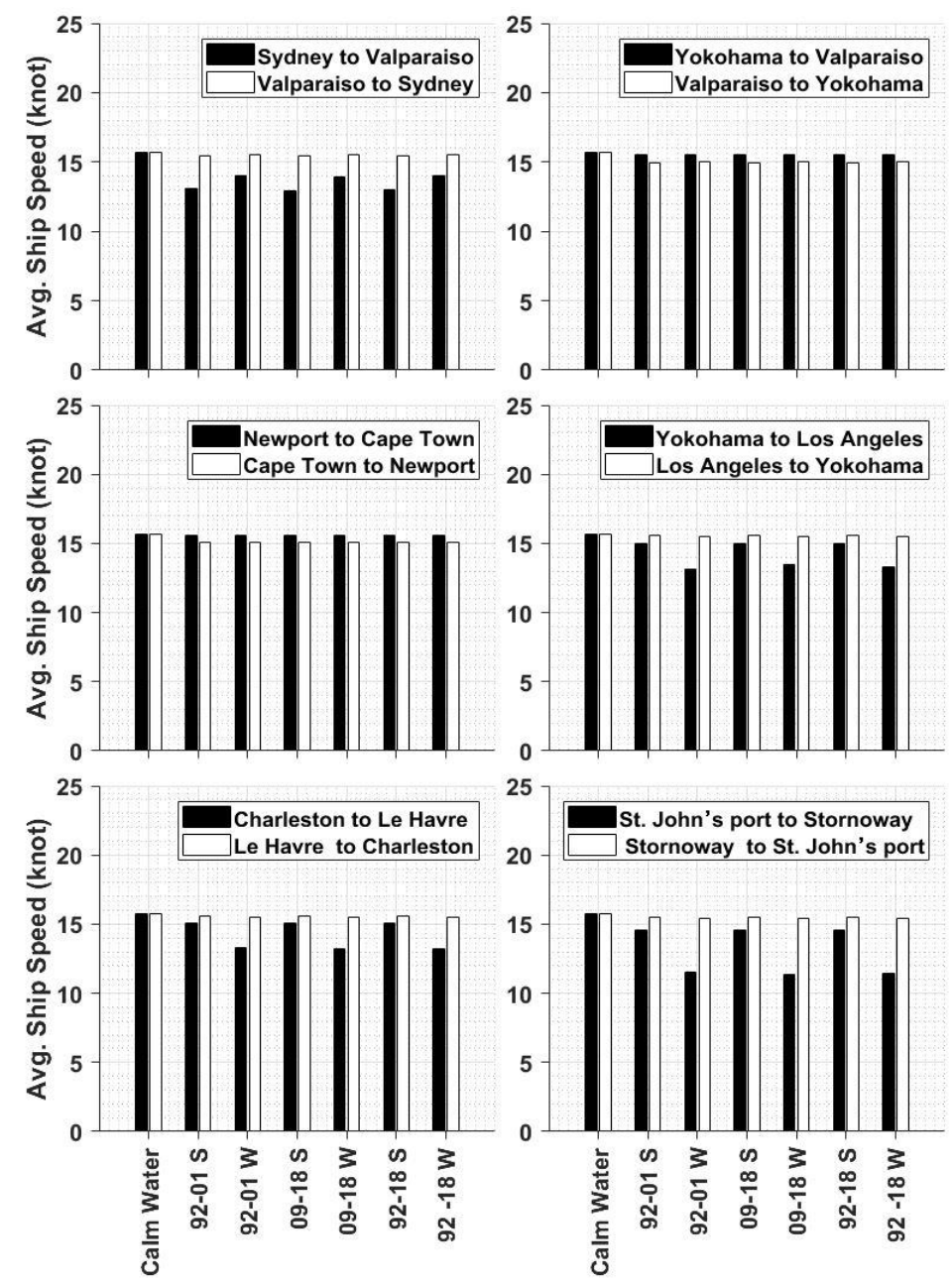

Fig. 30 Average ship speed for VLCC ship for different navigation routes (in knots)

\section{Discussion and Conclusions}

Worldwide oceanic wind and wave conditions for the last 27 years were downloaded from ECMWF website. These were then analysed as per the "summer", "winter" and "tropical" region as defined in international Loadline regulation. Added wave resistance as per wave conditions existing in the ocean were considered. Similarly, wind forces and moment as per the wind conditions existing in the ocean were considered. The comparison was done for the initial 10 years, last 10 years and 27 years of averaged data. To capture the effect of wind/ wave direction, simulations were carried out for to and fro voyage between 2 ports. Travel time and fuel consumption for 6 different oceanic voyages were calculated. The above analysis was carried out for three different ship types, i.e. VLCC tanker, DTMB 5415 ship and PCC ship. The main conclusions of this paper are:

i. It is observed that the wave and wind angle in oceans is not the same. Wave/ wind activity in the Southern Ocean, North Atlantic and North Pacific Ocean region has increased in recent years. The Southern Ocean is the roughest ocean on Earth, and thereby the most dangerous for a voyage. Sudden variation of the mean wave height, wave period and wind speed can be observed at the boundaries of the load line zones. This leads to the question whether the existing load line boundaries need to be redrawn. However, the recent changes in the wave/ wind conditions is not so significant as to influence propulsive efficiency of ship navigation. 
ii. It is observed that for all the 6 voyages, the difference between fuel consumption, travel time, average ship speed is significant for to and fro direction. Sydney Valparaiso route shows the most significant difference in fuel consumption, average ship speed and voyage duration between to and fro direction. Travelling from "Sydney to Valparaiso" requires more time/ fuel than "Valparaiso to Sydney" in both summer and winter seasons. This difference is due to the direction of wave and wind. The ship mainly encounters head waves during Sydney to Valparaiso voyage, and following waves during Valparaiso to Sydney voyage.

iii. It is observed that voyage time, average ship speed and fuel consumption of the voyages also varies as per "summer" and "winter" season. For example, Yokohama to Los Angeles voyage shows the maximum difference in fuel consumption and time of travel between "summer" and "winter" season. During this voyage, travel time and fuel consumption are higher in "winter" as compared to "summer". During this voyage, the average ship speed is higher in "summer" as compared to "winter".

iv. Wave height/ period has more impact on ship's resistance as compared to wind speed. The tropical region is suitable for voyage in any season. This is because there is marginal change in wind speed and wave height/ period in this region. Geographically, great ellipse trajectory is the shortest route. However, fuel consumption, average ship speed and travel time depend on wave/ wind conditions and their direction during the voyage and the ship type. For some voyages, rough weather conditions could become a safety issue. Optimal ocean routing techniques should consider these aspects in their algorithms. 


\section{APPENDIX A:}

Table 2 Loadline zones date wise

\begin{tabular}{|l|l|l|}
\hline Zone & Summer & \multicolumn{2}{l|}{ Winter } \\
\hline 1 & 16 Oct -15 Apr & \multicolumn{1}{l|}{16 Apr -15 Oct } \\
\hline 2,3 & Whole Year & \multicolumn{2}{l|}{$\begin{array}{l}1 \text { Mar }-30 \text { June } \\
1-30 \text { Nov }\end{array}$} \\
\hline 4 & $\begin{array}{l}1 \text { July }-31 \text { Oct } \\
1 \text { Dec }-28 / 29 \text { Feb }\end{array}$ & 1 Apr -30 Nov \\
\hline 5 & 1 Dec -31 Mar & 1 Apr -31 Oct \\
\hline 6 & 1 Nov -31 Mar & 16 Oct -15 Apr \\
\hline 7 & 16 Apr -15 Oct & 21 Jan -30 Apr \\
\hline 8 & 1 May -20 Jan & 1 Dec -30 Apr \\
\hline 9 & 1 May -30 Nov & 1 Sept -31 May \\
\hline 10 & 1 June -31 Aug & 1 Apr -30 Nov \\
\hline 11 & 1 Dec -31 Mar & 16 Oct -15 Apr \\
\hline 12 & 16 Apr -15 Oct & 1 Nov -31 March \\
\hline 13 & 1 Apr -31 Oct & 1 Nov -15 July \\
\hline 14 & 16 July -31 Oct & 16 Feb -15 Dec -15 Feb \\
\hline 15 & 1 Dec -30 Apr & Nov \\
\hline 16 & &
\end{tabular}

\section{APPENDIX B:}

$$
\begin{aligned}
& \sin ^{2} \sigma_{a}=\left(\cos U_{2} * \sin \Delta \lambda\right)^{2}+\left(\cos U_{1} * \sin U_{2}-\sin U_{1} * \cos U_{2} * \cos \Delta \lambda\right)^{2} \\
& \cos \sigma_{a}=\sin U_{1} * \sin U_{2}+\cos U_{1} * \cos U_{2} * \cos \Delta \lambda \\
& \sin \alpha=\cos U_{1} * \cos U_{2} * \sin \Delta \lambda / \sin \sigma_{a} \\
& \cos 2 \sigma_{m}=\cos \sigma_{a}-2 \sin U_{1} * \sin U_{2} / \cos ^{2} \alpha \\
& \mathrm{uu}^{2}=(\cos \alpha)^{2} *\left(\mathrm{R}_{\mathrm{EQ}}{ }^{2}-\mathrm{R}_{P L}{ }^{2}\right) / \mathrm{R}_{P L}^{2} \\
& \mathrm{AA}=1+\frac{u u^{2}}{256}\left[64+u u^{2}\left(5 * u u^{2}-12\right)\right] \\
& \tan (U)=(1-f) * \tan (\varphi) \\
& f=\left(R_{E Q}-R_{P L}\right) / R_{E Q}
\end{aligned}
$$


Numerical simulation of ship navigation

in rough seas based on ECMWF data
Patil Prasad Vinayak,

Chelladurai Sree Krishna Prabu, Nagarajan Vishwanath, Sha Om Prakash

\section{ACKNOWLEDGEMENT:}

The first author expresses his sincere gratitude to Prof. P. K. Bhaskaran for his constant support and help during the weather data processing.

\section{REFERENCES}

[1] C.B. Smith, Extreme Waves and Ship Design, in: 10th Int. Symp. Pract. Des. Ships Other Float. Struct., 2007.

[2] I.R. Young, Seasonal variability of the global ocean wind and wave climate, Int. J. Climatol. 19 (1999) 931-950. https://doi.org/10.1002/(SICI) 1097-0088(199907)19:9<931::AID-JOC412>3.0.CO;2-O

[3] C. Chen, K. Sasa, T. Ohsawa, M. Kashiwagi, J. Prpić-Oršić, T. Mizojiri, Comparative assessment of NCEP and ECMWF global datasets and numerical approaches on rough sea ship navigation based on numerical simulation and shipboard measurements, Appl. Ocean Res. 101 (2020). https://doi.org/10.1016/j.apor.2020.102219

[4] S. Luo, N. Ma, Y. Hirakawa, Evaluation of resistance increase and speed loss of a ship in wind and waves, J. Ocean Eng. Sci. 1 (2016) 212-218. https://doi.org/10.1016/j.joes.2016.04.001

[5] J.M.J. Journee, Prediction of Speed and Behaviour of a Ship in a Seaway, Int. Shipbuild. Prog. 23 (1976) 1-24. https://doi.org/10.3233/ISP-1976-2326501

[6] J.M.J. Journee, Ship Routeing for Optimum Performance, Trans. IME. (2001) 1-21.

[7] M. Roh, Determination of an economical shipping route considering the effects of sea state for lower fuel consumption, Int. J. Nav. Archit. Ocean Eng. 5 (2013) 246-262. https://doi.org/10.2478/IJNAOE$\underline{2013-0130}$

[8] N. Degiuli, I. Martić, A. Farkas, Environmental aspects of total resistance of container ship in the north atlantic, J. Sustain. Dev. Energy, Water Environ. Syst. 7 (2019) 641-655. https://doi.org/10.13044/j.sdewes.d7.0267

[9] D. Park, Y. Kim, M. Seo, J. Lee, Study on added resistance of a tanker in head waves at different drafts, Ocean Eng. 111 (2016) 569-581. https://doi.org/10.1016/j.oceaneng.2015.11.026

[10] D. Matulja, M. Sportelli, C. Guedes Soares, J. Prpic-Orsic, Estimation of Added Resistance, Brodo Gradnja. 62 (2011) 259-264.

[11] N. Degiuli, I. Ćatipović, I. Martić, A. Werner, V. Čorić, Increase of ship fuel consumption due to the added resistance in waves, J. Sustain. Dev. Energy, Water Environ. Syst. 5 (2017) 1-14. https://doi.org/10.13044/j.sdewes.d5.0129

[12] M. Kuroda, K. Takagi, M. Tsujimoto, J. Fujisawa, Measurement of Added Resistance in Irregular Waves and Estimation of the Long-period Components, J. Japan Soc. Nav. Archit. Ocean Eng. 24 (2016) 183190. https://doi.org/10.2534/jjasnaoe.24.181

[13] J.H. Seo, C.M. Lee, J.W. Yu, J.E. Choi, I. Lee, Power increase and propulsive characteristics in regular head waves of KVLCC2 using model tests, Ocean Eng. $216 \quad$ (2020) 108058. https://doi.org/10.1016/j.oceaneng.2020.108058

[14] A.K. Dash, V. Nagarajan, O.P. Sha, Bifurcation analysis of a high-speed twin-propeller twin-rudder ship maneuvering model in roll-coupling motion, Nonlinear Dyn. 83 (2016) 2035-2053. https://doi.org/10.1007/s11071-015-2463-9

[15] A.K. Dash, P.P. Chandran, M.K. Khan, V. Nagarajan, O.P. Sha, Roll-induced bifurcation in ship maneuvering under model uncertainty, J. Mar. Sci. Technol. 21 (2016) 689-708. https://doi.org/10.1007/s00773-016-0382-1

[16] H. Yasukawa, R. Sakuno, Application of the MMG method for the prediction of steady sailing condition and course stability of a ship under external disturbances, J. Mar. Sci. Technol. (2019). https://doi.org/10.1007/s00773-019-00641-4

[17] M. Tsujimoto, H. Orihara, Performance prediction of full-scale ship and analysis by means of on- board monitoring ( Part 1 ship performance prediction in actual seas ), J. Mar. Sci. Technol. 24 (2019) 16-33. https://doi.org/10.1007/s00773-017-0523-1

[18] S. Liu, M. Loh, W. Leow, H. Akzonobel, H. Singapore, B. Com, Shang, A. Papanikolaou, Rational Processing of Monitored Ship Voyage Data for Improved Operation, Appl. Ocean Res. 104 (2020) 102363. https://doi.org/10.1016/j.apor.2020.102363 
Patil Prasad Vinayak,

Chelladurai Sree Krishna Prabu,

Nagarajan Vishwanath, Sha Om Prakash
Numerical simulation of ship navigation in rough seas based on ECMWF data

[19] C. Chen, S. Shiotani, K. Sasa, Numerical ship navigation based on weather and ocean simulation, Ocean Eng. 69 (2013) 44-53. https://doi.org/10.1016/j.oceaneng.2013.05.019

[20] J. Prpić-Oršić, K. Sasa, M. Valčić, O.M. Faltinsen, Uncertainties of ship speed loss evaluation under real weather conditions, J. Offshore Mech. Arct. Eng. 142 (2020) 6-10. https://doi.org/10.1115/1.4045790

[21] M. Tsujimoto, M. Kuroda, K. Shibata, N. Sogihara, K. Takagi, On a Calculation of Decrease of Ship Speed in Actual Seas, J. Japan Soc. Nav. Archit. Ocean Eng. 9 (2009) 79-85. https://doi.org/10.2534/jjasnaoe.9.79

[22] H.N. Psaraftis, C.A. Kontovas, Balancing the economic and environmental performance of maritime transportation, Transp. Res. Part D Transp. Environ. 15 (2010) 458-462. https://doi.org/10.1016/j.trd.2010.05.001

[23] A. Maki, Y. Akimoto, Y. Nagata, S. Kobayashi, E. Kobayashi, S. Shiotani, T. Ohsawa, N. Umeda, A new weather-routing system that accounts for ship stability based on a real-coded genetic algorithm, J. Mar. Sci. Technol. 16 (2011) 311-322. https://doi.org/10.1007/s00773-011-0128-Z

[24] Y. Lin, M. Fang, R.W. Yeung, The optimization of ship weather-routing algorithm based on the composite influence of multi-dynamic elements, Appl. Ocean Res. 43 (2013) 184-194. https://doi.org/10.1016/j.apor.2013.07.010

[25] M.C. Fang, Y.H. Lin, The optimization of ship weather-routing algorithm based on the composite influence of multi-dynamic elements (II): Optimized routings, Appl. Ocean Res. 50 (2015) 130-140. https://doi.org/10.1016/j.apor.2014.12.005

[26] I. Watanabe, H. Ohtsubo, Analysis of the accident of the M V N Nakhodka . Part 1. Estimation of wave loads *, J. Mar. Sci. Technol. (1998) 171-180. https://doi.org/10.1007/BF02492932

[27] S.M. Varlamov, J.H. Yoon, N. Hirose, H. Kawamura, K. Shiohara, Simulation of the oil spill processes in the Sea of Japan with regional ocean circulation model, J. Mar. Sci. Technol. 4 (2000) 94-107. https://doi.org/10.1007/s007730050012

[28] F. Fedele, C. Lugni, A. Chawla, The sinking of the El Faro: Predicting real world rogue waves during Hurricane Joaquin, Sci. Rep. 7:11188 (2017) 1-15. https://doi.org/10.1038/s41598-017-11505-5

[29] A. Ribal, I.R. Young, 33 years of globally calibrated wave height and wind speed data based on altimeter observations, Sci. Data. 6 (2019) 77. https://doi.org/10.1038/s41597-019-0083-9

[30] I.R. Young, E. Sanina, A. V Babanin, Calibration and Cross Validation of a Global Wind and Wave Database of Altimeter, Radiometer, and Scatterometer Measurements, J. Atmos. Ocean. Technol. 34 (2017) 1285-1306. https://doi.org/10.1175/JTECH-D-16-0145.1

[31] I.R. Young, S. Zieger, A. V Babanin, Global trends in wind speed and wave height, Science (80-. ). 332 (2011) 451-455. https://doi.org/10.1126/science.aav9527

[32] A. Meucci, I.R. Young, O. Breivik, Wind and wave extremes from atmosphere and wave model ensembles, J. Clim. (2018) 8819-8843. https://doi.org/10.1175/JCLI-D-18-0217.1

[33] I.R. Young, M.A. Donelan, On the determination of global ocean wind and wave climate from satellite observations, Remote Sens. Environ. 215 (2018) 228-241. https://doi.org/10.1016/j.rse.2018.06.006

[34] International Maritime Organization, The International Convention on Load Lines, 2005. https://doi.org/10.1093/nq/193.21.456

[35] Y. Yoshimura, Mathematical Model for the Manoeuvring Ship Motion in Shallow Water, J. Kansai Soc. Nav. Archit. Japan. (1986).

[36] K. Kijima, NakiriYasuaki, On the Practical Prediction Method for Ship Manoeuvring Characteristics, in: MARSIM'03 Proc., 2003: pp. 615-623.

[37] B. Taskar, P. Andersen, Benefit of speed reduction for ships in different weather conditions, Transp. Res. Part D Transp. Environ. 85 (2020) 102337. https://doi.org/10.1016/j.trd.2020.102337

[38] H. Lindstad, B.E. Asbjørnslett, A.H. Strømman, Reductions in greenhouse gas emissions and cost by shipping at lower speeds, Energy Policy. $39 \quad$ (2011) 3456-3464. https://doi.org/10.1016/j.enpol.2011.03.044

[39] American Bureau of Shipping, ABS Guidance Notes on Ship Vibration, (2018) 1-84.

[40] M. Kim, O. Hizir, O. Turan, A. Incecik, Numerical studies on added resistance and motions of KVLCC2 in head seas for various ship speeds, Ocean Eng. 140 (2017) 466-476. https://doi.org/10.1016/j.oceaneng.2017.06.019

[41] Bentley Systems, Maxsurf Motions User Manual, 2013.

[42] V. Aribenchi, Dynamics Of Asymmetrical Configurations Of Catamaran Hull Forms, 2017. 
Numerical simulation of ship navigation in rough seas based on ECMWF data

Patil Prasad Vinayak, Chelladurai Sree Krishna Prabu, Nagarajan Vishwanath, Sha Om Prakash

[43] M. Kim, O. Hizir, O. Turan, S. Day, A. Incecik, Estimation of added resistance and ship speed loss in a seaway, Ocean Eng. 141 (2017) 465-476. https://doi.org/10.1016/j.oceaneng.2017.06.051

[44] D.M. Park, J.H. Lee, Y.W. Jung, J. Lee, Y. Kim, F. Gerhardt, Experimental and numerical studies on added resistance of ship in oblique sea conditions, Ocean Eng. 186 (2019) 106070. https://doi.org/10.1016/j.oceaneng.2019.05.052

[45] T. Fujiwara, M. Ueno, T. Nimura, Estimation of Wind Forces and Moments acting on Ships, J. Soc. Nav. Archit. Japan. 1998 (1998) 77-90. https://doi.org/10.2534/jjasnaoe1968.1998.77

[46] Det Norske Veritas, Environmental conditions and environmental testing, 2010. https://doi.org/10.1109/INTLEC.1993.388591

[47] P.D. Groves, Principles of GNSS, Inertial, and Multisensor Integrated Navigation Systems, 2014. https://doi.org/10.1017/S0373463313000672

[48] T.P. Hsu, T.H. Hsieh, Evaluation and Execution of Great Elliptic Sailing, J. Navig. 70 (2017) 10231040. https://doi.org/10.1017/S0373463317000108

[49] T. Vincenty, Direct and inverse solutions of geodesics on the ellipsoid with application of nested equations, Surv. Rev. 23 (1975) 88-93. https://doi.org/10.1179/sre.1975.23.176.88

[50] T.I. Fossen, Guidance and control of ocean vehicles, 1994. https://doi.org/10.1016/0005-1098(96)823314. https://doi.org/10.1016/0005-1098(96)82331-4

[51] T.R.I. of N. Architects, Significant Ships of 1996, 2004, 2007, 2008,2010, 2012, 2013, 2016.pdf, n.d.

[52] J.R. Bidlot, B. Hansen, P.A.E.. Janssen, Wave modelling and operational forecasting at ECMWF, Oper. Oceanogr. Chall. Eur. Co-Operation. 62 (1997) 206-213. https://doi.org/10.1016/S0422-9894(97)80027$\underline{X}$

\section{List of Symbols:}

$a_{H} \quad$ Ratio of additional lateral force $S_{B H} \quad$ Wetted surface area of bare hull induced on ship hull by rudder action to the rudder force

$A_{R} \quad$ Rudder area

$A_{T} \quad$ Transverse projected area of the ship

$A_{L}$

A

$A_{3}$

$$
\begin{aligned}
& B_{1}, \\
& B_{3}
\end{aligned}
$$

$B_{W L}$

$C_{B}$

$C_{M}$

$C 1, C 2$

Lateral projected area of the ship

$A_{2}$, coefficients

of

polynomial

representing propeller open water

thrust characteristics

$B_{1}, \quad B_{2}$, coefficients of

representing propeller open water

torque characteristics

Waterline Beam

Block coefficient

Midship Section Area Coefficient

Autopilot gain coefficients
$S(\omega) \quad$ Wave spectrum

$T \quad$ Ship's draft

$T_{P} \quad$ Mean wave period [MWP]

Thrust deduction factor 
Patil Prasad Vinayak,

Chelladurai Sree Krishna Prabu,

Nagarajan Vishwanath, Sha Om Prakash

$C_{X}\left(\psi_{A}\right), \quad$ Fujiwara's wind force coefficients

$C_{Y}\left(\psi_{A}\right)$,

$C_{N}\left(\psi_{A}\right)$,

$C_{K}\left(\psi_{A}\right)$

$D_{P} \quad$ Propeller diameter

ds $\quad$ Geodetic distance between two points $\quad X_{P}$

$H_{1 / 3} \quad$ Significant wave height

$h \quad$ Altitude (height)

$X_{R}$

$I_{P P} \quad$ Mass rotary mass moment of inertia of $X_{A W}$ propeller

$I_{z z} \quad$ Mass moment of inertia about $\mathrm{Z}$ axis $\quad X_{W}$

$I_{Z Z}{ }^{\prime} \quad$ Nondimensional mass moment of $w_{P 0}$ inertia about $\mathrm{Z}$ axis

$=I_{Z Z} /\left(0.5 * \rho^{*} L^{4} * T\right)$

$J_{z z} \quad$ Added mass moment of inertia about $\beta$ $\mathrm{Z}$ axis

$J_{\mathrm{ZZ}}{ }^{\prime} \quad$ Nondimensional added mass moment $\varsigma$ of inertia about $\mathrm{Z}$ axis

$=J_{\mathrm{ZZ}} /\left(0.5 * \rho^{*} L^{4} * T\right)$

$J_{P P} \quad$ Added rotary mass moment of inertia $\theta \quad$ Pitch angle

of propeller

$J_{p} \quad$ Propeller advance coefficient

$K_{T} \quad$ Propeller thrust coefficient

$K_{Q} \quad$ Propeller torque coefficient

$L_{O A} \quad$ Overall length of ship

$L_{P P} \quad$ Length between perpendiculars

$\mathrm{Lu} \quad$ Integral length scale

$m \quad$ Mass of ship $v$

$x_{G}$,

$y_{G}$,

$z_{G}$

Numerical simulation of ship navigation in rough seas based on ECMWF data

coordinate at 10 meter height

Sway velocity

Hydrodynamic hull force in surge direction

Propeller force in surge direction

Rudder force in surge direction

Coordinates of centre of mass

Added wave resistance in surge direction

Wind force in surge direction

Effective wake fraction coefficient

Ship drift angle

Wave amplitude

$\lambda \quad$ longitude

$\rho_{A} \quad$ Air density

$\eta_{R} \quad$ Relative rotative efficiency

$\rho \quad$ Seawater density

$\sigma \quad$ Standard deviation of wind speed

$\sigma_{a} \quad$ Angular distance on ellipsoid

$\phi \quad$ Roll angle 
Numerical simulation of ship navigation

in rough seas based on ECMWF data

$m^{\prime} \quad$ Nondimensional mass of ship

$=m /\left(0.5 * \rho * L^{2} * T\right)$

$n \quad$ Propeller revolutions per second

$P_{D} \quad$ Engine power

p Roll rate

$Q_{E} \quad$ Engine torque

$Q_{P} \quad$ Propeller torque

$R_{a w} \quad$ Added wave resistance

$R_{E Q} \quad$ Equatorial radius of the Earth

$R_{P L} \quad$ Polar radius of the Earth

$r \quad$ Yaw rate
Patil Prasad Vinayak, Chelladurai Sree Krishna Prabu, Nagarajan Vishwanath, Sha Om Prakash

$\varphi \quad$ Latitude

$\begin{array}{ll}\psi & \text { Heading angle } \\ \psi_{\text {waveE }} & \text { Wave angle w.r.t. North }\end{array}$

$\psi_{\text {wave }} \quad$ Wave angle w.r.t. ship

$\psi_{D} \quad$ Desired course heading angle

$\psi_{A} \quad$ Resultant wind angle

$\psi_{w} \quad$ Wind angle w.r.t North

$\omega_{\text {wave }}$ Circular frequency of the wave

$\omega_{m} \quad$ Modal frequency corresponding to the highest peak of the spectrum

$\omega_{e} \quad$ Encounter frequency

\section{List of Acronyms:}

CDF Cumulative Distribution Function

CDO Climate Data Operators

DTMB David Taylor Model Basin

ECMWF European Centre for Medium-Range Weather Forecasts. ECMWF is an independent intergovernmental organisation supported by most of the nations of Europe. ECMWF aims to provide accurate medium-range global weather forecasts.

EEDI Energy Efficiency Design Index

ERS European Remote-Sensing Satellite

ERA ECMWF Re-Analysis

ETA Estimated Time of Arrival

GES Great ellipse sailing

IMO International Maritime Organization

NCEP- FNL National Centers for Environmental Prediction - Final analysis. NCEP is USA based agency which provides information on the future state of weather, land surface, ocean, sea ice, short-term climate, and ecosystems.

PCC Pure Car Carrier

SFOC Specific fuel oil consumption 
Patil Prasad Vinayak,

Chelladurai Sree Krishna Prabu,

Nagarajan Vishwanath, Sha Om Prakash

TFC

Total Fuel Consumption

VLCC

Very Large Crude Carrier
Numerical simulation of ship navigation in rough seas based on ECMWF data

The time derivative of a variable is denoted by a dot above the variable e.g. $\dot{n}$ is the time derivative of $n$.

Subscripts:

P Propeller

R Rudder

H Hull

W Wind

$\{\mathrm{S}\}$ starboard

$\{\mathrm{P}\}$ Port

\section{Superscripts:}

( ' ) represents the non-dimensional value.

Submitted: $\quad$ 16.10.2020. $\quad$ Author 1, Prasad Vinayak Patil

Research scholar,

Accepted: 26.02.2021. Department of Ocean Engineering \& Naval Architecture

Indian Institute of Technology Kharagpur

Kharagpur-721302, West Bengal, India

email: prasad.phdiitkgp@gmail.com

Author 2, Sree Krishna Prabu Chelladurai

Research scholar,

Department of Ocean Engineering \& Naval Architecture

Indian Institute of Technology Kharagpur

Kharagpur-721302, West Bengal, India

Author 3, Dr. Vishwanath Nagarajan,

Associate Professor,

Department of Ocean Engineering \& Naval Architecture

Indian Institute of Technology Kharagpur

Kharagpur-721302, West Bengal, India

email: vishwanath_n@naval.iitkgp.ernet.in

Author 4, Om Prakash Sha

Professor,

Department of Ocean Engineering \& Naval Architecture

Indian Institute of Technology Kharagpur

Kharagpur-721302, West Bengal, India 